\title{
Propagation of the Madden-Julian Oscillation and scale interaction with the diurnal cycle in a high-resolution GCM
}

\author{
Simon C. Peatman • Adrian J. Matthews • \\ David P. Stevens
}

Received: 10 November 2014 / Accepted: 4 February 2015 / Published online: 15 February 2015

(c) The Author(s) 2015. This article is published with open access at Springerlink.com

\begin{abstract}
The Madden-Julian Oscillation (MJO) is the chief source of tropical intra-seasonal variability, but is simulated poorly by most state-of-the-art GCMs. Common errors include a lack of eastward propagation at the correct frequency and zonal extent, and too small a ratio of eastward- to westward-propagating variability. Here it is shown that HiGEM, a high-resolution GCM, simulates a very realistic MJO with approximately the correct spatial and temporal scale. Many MJO studies in GCMs are limited to diagnostics which average over a latitude band around the equator, allowing an analysis of the MJO's structure in time and longitude only. In this study a wider range of diagnostics is applied. It is argued that such an approach is necessary for a comprehensive analysis of a model's MJO. The standard analysis of Wheeler and Hendon (Mon Wea Rev 132(8):1917-1932, 2004; WH04) is applied to produce composites, which show a realistic spatial structure in the MJO envelopes but for the timing of the peak precipitation in the inter-tropical convergence zone, which bifurcates the MJO signal. Further diagnostics are developed to analyse the MJO's episodic nature and the "MJO inertia" (the tendency to remain in the same $\mathrm{WH} 04$ phase from one day to the next). HiGEM favours phases 2, 3, 6 and 7; has too much MJO inertia; and dies out too frequently in phase 3. Recent research has shown that a key feature of the MJO
\end{abstract}

S. C. Peatman $(\varangle) \cdot$ A. J. Matthews · D. P. Stevens Centre for Ocean and Atmospheric Sciences, School of Mathematics, University of East Anglia, Norwich NR4 7TJ, UK

e-mail: s.peatman@reading.ac.uk

\section{A. J. Matthews}

Centre for Ocean and Atmospheric Sciences, School of Environmental Sciences, University of East Anglia, Norwich NR4 7TJ, UK is its interaction with the diurnal cycle over the Maritime Continent. This interaction is present in HiGEM but is unrealistically weak.

Keywords HiGEM - MJO - Maritime Continent · Diurnal cycle $\cdot$ Diagnostics

\section{Introduction}

The Madden-Julian Oscillation (MJO; Madden and Julian 1971, 1972, 1994; Zhang 2005) is the greatest source of variability on intra-seasonal time scales throughout the tropics. It consists of alternate large-scale envelopes of active and suppressed convection propagating slowly $\left(\sim 5 \mathrm{~m} \mathrm{~s}^{-1}\right)$ eastwards from the Indian Ocean to the Pacific Ocean, and an associated planetary-scale circulation. Although referred to as an oscillation, the MJO is in fact episodic, with MJO "events" being initiated at any location within its propagation region (Matthews 2008). The eastward propagation arises from a complex interaction between dynamical and convective processes (e.g., Matthews 2000; Seo and Kim 2003; Hsu and Lee 2005). One interpretation of the MJO is that it consists of a MatsunoGill-style reponse (Matsuno 1966; Gill 1980) to a moving heat source (e.g., Chao 1987). An eastward-propagating equatorial Kelvin wave and a westward-propagating equatorial Rossby wave are forced by equatorial diabatic heating. The circulation anomalies of these waves together act to enhance convection to the east of the active MJO envelope and shut off convection to the west, thus shifting the convective region slowly eastward (Matthews 2000).

Recent research has shown that over the Maritime Continent (the equatorial archipelago at $95^{\circ}-160^{\circ} \mathrm{E}$, consisting of Indonesia, Philippines and Papua New Guinea) the 
precipitation anomalies associated with the MJO over land are very different from the surrounding large-scale envelope (Peatman et al. 2014). For example, when the MJO is suppressed over the Maritime Continent region as a whole there is a wet anomaly over the island of New Guinea, so a gap appears in the large-scale MJO envelope. This behaviour was attributed to an interaction with the strong diurnal cycle of precipitation over the Maritime Continent islands (e.g., Qian 2008; Teo et al. 2011; Biasutti et al. 2012). This diurnal cycle is due to the relative thermal inertias of the land and ocean. As the land warms faster than the ocean during the day, onshore breezes converge and force moist air upwards, causing strong convective rainfall which peaks in the afternoon and evening, dying out overnight. The corresponding diurnal peak over the ocean occurs in the early morning and is significantly weaker than that over land (see Peatman et al. 2014, Figs. 2, 3).

Peatman et al. (2014) showed that the diurnal cycle is triggered most strongly just to the east of an advancing active MJO envelope. Thus, the greatest enhancement of the diurnal cycle occurs about one-eighth of an MJO cycle before the most active MJO conditions arrive. Since the vast majority $(81 \%)$ of the MJO variability in daily mean precipitation over the Maritime Continent islands is accounted for by changes in the diurnal cycle, Peatman et al. (2014) concluded that the gaps in the large-scale envelopes are caused by the strong diurnal signal rectifying onto the daily mean, thus determining the spatial structure of the MJO. They showed also that the common assumption that outgoing longwave radiation (OLR) is a good proxy for rainfall breaks down over the islands, with precipitation tending to peak ahead of the OLR signal in the MJO cycle.

These phenomena were explained by Peatman et al. (2014) in terms of atmosphere-land interactions. However, atmosphere-ocean interactions, which are known to be important in the propagation of the MJO in general (e.g., Woolnough et al. 2007), are still likely to be important in the Maritime Continent since significant sea surface temperature (SST) anomalies associated with the MJO can exist there (e.g., Hendon and Glick 1997). Indeed, the tropical ocean diurnal cycle is known to interact with the MJO, with the diurnal cycle of SST affecting the initiation and intensity of MJO events (Seo et al. 2014), and the MJO modulating the effect of the diurnal cycle of insolation on the ocean mixed layer ( $\mathrm{Li}$ et al. 2013; Matthews et al. 2014). In particular, the diurnal cycle of SST is likely to affect the offshore convection which occurs strongly in the Maritime Continent region.

The interaction between the MJO and the Maritime Continent diurnal cycle has clear implications for forecasting and for modelling in general. A failure to simulate this interaction is likely to lead to the strongest MJO convection simply peaking in phase with the large-scale conditions, changing the radiation budget considerably. It has been shown (e.g., Neale and Slingo 2003) that errors in the simulation of Maritime Continent convection can cause errors to propagate globally in models. Therefore, the behaviour of the MJO over the Maritime Continent should be treated as a matter of great importance by climate modellers, and a thorough review of a model's ability to simulate the MJO should consider this behaviour. However, the MJO itself is generally simulated poorly by general circulation models (GCMs). According to Zhang (2005), common problems include a lack of eastward-propagating intra-seasonal variability altogether, convection failing to couple correctly to the dynamics, and convection being incorrectly distributed in space. Only around one-third of the Coupled Model Intercomparison Project Phase 5 (CMIP5; Taylor et al. 2012) models studied by Hung et al. (2013) exhibit a peak in the OLR power spectrum in the MJO region of wavenumber-frequency space, many have an overreddened spectrum due to equatorial precipitation being too persistent, and only one model has realistic eastward propagation. Hung et al. (2013) did not use the High-resolution Global Environmental Model (HiGEM), used in this study (see Sect. 2.1), but they did analyse two versions of the Hadley Centre Global Environmental Model (HadGEM), on which HiGEM is based. Neither had a peak in the MJO region of wavenumber-frequency space; the ratio of eastward- to westward-propagating variability was $\sim 1.5$ in the Indian Ocean and just under 1 in the west Pacific (the respective values in observations were $\sim 3.5$ and $\sim 2.5$ ).

There are a few diagnostics which are frequently used in the literature to determine the skill of climate models at simulating the MJO. For example, wavenumber-frequency spectra of OLR (Wheeler and Kiladis 1999) provide a clear first indication of whether MJO-like variability exists (i.e., Does a model have eastward-propagating convectivelycoupled variability on intra-seasonal time scales at a realistic zonal wavenumber?). Such diagrams were used by Lin et al. (2006) and Hung et al. (2013) to compare the MJO in CMIP3 and CMIP5 models resepectively, and by Zhang (2005) to provide an overview of GCMs' MJO skill. The Climate and Ocean-Variability, Predictability and Change (CLIVAR) MJO Working Group (MJOWG) has attempted to standardize MJO model analysis by deciding upon a limited set of diagnostics, designed to provide a consistent, coherent way of analysing and comparing models. MJOWG diagnostics include maps of intra-seasonal variance, time spectra and wavenumber-frequency spectra, mono- and multi-variate empirical orthogonal functions (EOFs), MJO composites and inter-annual variability. Crueger et al. (2013) went further and combined just two quantities - the ratio of eastward to westward spectral power and the fraction of variance explained by the leading two EOFs of OLR - into a single metric, the "MJO score". 
A shortcoming of many of the diagnostics commonly used is that they do not consider the full structure of the MJO. For example, finding a realistic amount of spectral power in the eastward part of the power spectrum around MJO frequencies and zonal wavenumbers does not mean that the convective envelopes have the correct shape or internal structure. The results of Peatman et al. (2014) suggest that, given the effect of the MJO on Maritime Continent land-based convection, and the effect of the Maritime Continent convection on the MJO itself, a full analysis of a model's ability to simulate the MJO must also take account of these more detailed features. This paper is an example of a more in-depth study into the MJO in a high-resolution model, which is able not only to assess the model's skill but also to give an indication of the possible knock-on effects of model biases and the reasons for their occurrence.

Section 2 of this paper gives an overview of the HiGEM model, the observational data used in the study and the types of diagnostics which will be employed. First, the MJO's basic structure will be examined (Sect. 3) then new diagnostics will be introduced to examine the MJO's episodic and sporadic nature (Sect. 4) and finally the scale interaction with the diurnal cycle will be investigated (Sect. 5). A summary of results and discussion are found in Sect. 6.

\section{Methodology}

\subsection{HiGEM Model}

The model used in this study is version 1.2 of the Highresolution Global Environmental Model (HiGEM; Shaffrey et al. 2009), based on version 1 of the UK Met Office Hadley Centre model (HadGEM1; Martin et al. 2006; Ringer et al. 2006). HiGEM has increased horizontal resolution $\left(5 / 6^{\circ}\right.$ latitude by $5 / 4^{\circ}$ longitude and 38 levels up to $39 \mathrm{~km}$ for the atmosphere, $1 / 3^{\circ}$ latitude by $1 / 3^{\circ}$ longitude and 40 levels down to $5.5 \mathrm{~km}$ for the ocean) and alterations to, amongst other things, the moisture diffusion scheme, surface flux calculations, snow-free sea ice albedo, and the treatment of run-off on frozen soil. The Third Hadley Centre Coupled Ocean-Atmosphere General Circulation Model (HadCM3, forerunner to HadGEM1) used a mass flux convection scheme based on Gregory and Rowntree (1990); the HadGEM1 scheme (also used by HiGEM) is a revised version of that used in HadCM3 with new parameterizations, new thermodynamic closures, and the diagnosis of deep and shallow convection as detailed in Table 1 of Martin et al. (2006). Integrations of HiGEM show many improvements compared with HadGEM1, including the sea surface temperature and representation of air-sea coupled processes in the tropical Pacific Ocean. Although the horizontal resolution is high by the standards of climate models, it is still very coarse compared with the scale of coastal features of the Maritime Continent islands, their mountain peaks and the straits between the islands. Therefore, the Maritime Continent land-sea and mountain-valley breeze circulations, which are key to the simulation of the diurnal cycle of precipitation, are a priori unlikely to be simulated realistically.

The integration used for this study was a contribution to the decadal prediction part of CMIP5. The run extends from 1957 to 2016, initialized from a control experiment. Historical greenhouse gas and aerosol forcings were used up to the model year 2005, and representative concentration pathway 4.5 (RCP4.5; Moss et al. 2010) thereafter. Output will be used from model year 2000 onwards since this coincides with the Tropical Rainfall Measuring Mission (TRMM) era; TRMM data are used to diagnose the real-life diurnal cycle of precipitation and its relationship with the MJO (see Sect. 2.2 below).

\subsection{Data}

The TRMM 3B42 data set (Simpson et al. 1996; Huffman et al. 2007) provides estimates of precipitation rate at three-hourly intervals on a $0.25^{\circ} \times 0.25^{\circ}$ grid. Data derived from microwave sensors are used wherever possible, with missing regions filled in using infra-red data from geostationary satellites. However, precipitation estimates derived from infra-red radiances have an inherent time lag of about three hours (Kikuchi and Wang 2008), and we shall be comparing precipitation data with OLR, so only the data from microwave instruments will be used in this study. The microwave-only, "high-quality" part of 3B42 is denoted 3B42HQ.

The Wheeler and Hendon (2004; hereafter,WH04) MJO indices are based on EOF analysis of a combined field of OLR, and zonal wind at $850 \mathrm{hPa}\left(u_{850}\right)$ and $200 \mathrm{hPa}\left(u_{200}\right)$. The principal components of the leading two EOFs are known as the Real-time Multivariate MJO series, RMM1 and RMM2, and the eight phases of the MJO are eight octants of the RMM1-RMM2 plane. The EOFs computed by WH04 are used in this study, and the RMM1 and RMM2 time series found by WH04 are used for diagnosing the MJO in observations. All analysis of the MJO will be for boreal winters (November to April) only, since this is when the MJO tends to be strongest. The date range used for 3B42HQ in this paper starts in November 1998 and ends in April 2013, and for HiGEM starts in November 2000 and ends in April 2015; thus, 15 boreal winters are used. Days with RMM amplitude $\sqrt{(\mathrm{RMM} 1)^{2}+(\mathrm{RMM} 2)^{2}}$ less than 1 are considered to have a weak MJO, and are excluded from composites and other analysis. 


\subsection{Diagnostics}

Several aspects of the modelled MJO will be investigated in Sects. 3, 4 and 5. The initial approach will be to seek evidence of convectively-coupled, eastward-propagating intraseasonal variability by finding the wavenumber-frequency spectrum of OLR, using the approach of Wheeler and Kiladis (1999). Once it is established there is a strong peak in the MJO region of the spectrum, we consider the spatial structure of this variability using EOF analysis and composites of daily mean precipitation, to confirm whether the shape of the anomalies in the intra-seasonal cycle resemble the observed MJO.

Phases of the MJO will be defined in the model using the approach of WH04, but dividing up the days of the model output depending on how they project onto the EOFs does not necessarily imply that those phases tend to occur in succession or that they persist for the right amount of time. Therefore, the time series of MJO phases will be analysed. New diagnostics will be presented which determine the frequency of occurrence of each phase, the mean RMM amplitude in each phase, and the amount of time the model tends to spend in each phase before the MJO either progresses to the next phase or decays. Furthermore, a climatology will be produced of all instances of propagation from one phase of the MJO to the next. These diagnostics will all be produced for both the observed MJO and that in HiGEM, and will be used to pinpoint precisely where biases exist and what physical processes require further attention in the model's development.

As described in Sect. 1, the results of Peatman et al. (2014) indicate that the interaction between the MJO and the diurnal cycle over the Maritime Continent is a key aspect of the MJO itself and is a significant factor in determining the precipitation over the Maritime Continent islands. Therefore, we wish this interaction to be reproduced faithfully by GCMs. Here, we use the same quantities plotted for observations by Peatman et al. (2014) in the discovery of this interaction. By comparision between observations and the model we investigate whether such an interaction exists in HiGEM, its strength and what aspects of the physics are incorrectly simulated.

\section{Existence of MJO variability}

Figure 1 shows the zonal wavenumber-frequency power spectrum of the equatorially symmetric part of the OLR field in HiGEM, relative to a background spectrum (Wheeler and Kiladis 1999). The spectrum shown is the mean over 96-day segments (overlapping by 60 days), summed over the latitude range $15^{\circ} \mathrm{S}-15^{\circ} \mathrm{N}$. There is a clear signal in the region representing the $\mathrm{MJO}$, with frequency

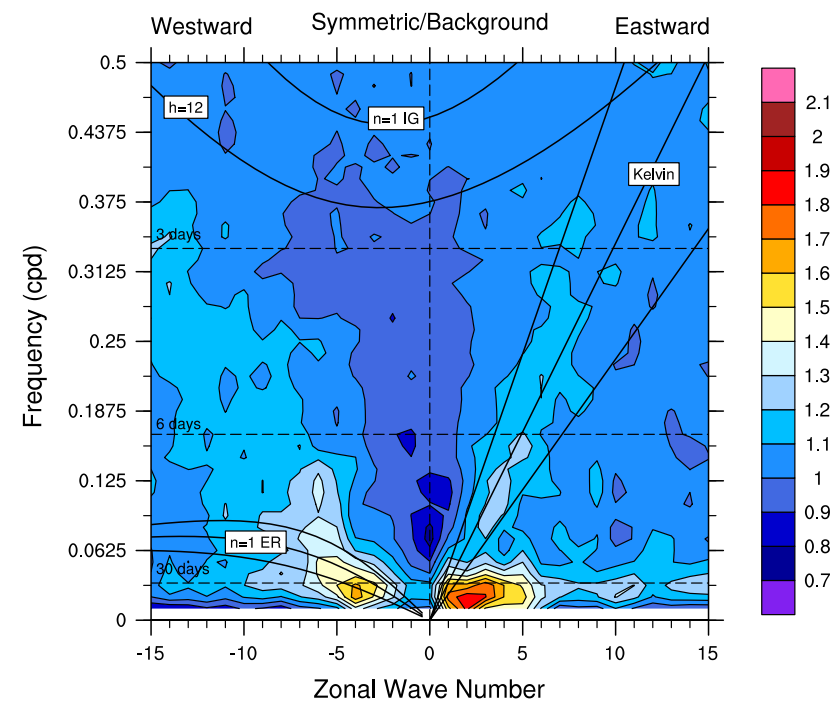

Fig. 1 Spectral power of the equatorially-symmetric part of the OLR field in HiGEM, summed over the range $15^{\circ} \mathrm{S}-15^{\circ} \mathrm{N}$, divided by the background spectrum (not shown). Hypothetical dispersion curves for families of equatorial waves are superimposed (ER equatorial Rossby, $I G$ inertio-gravity, $n$ mode number, $h$ equivalent depth; see Kiladis et al. 2009). This is the equivalent of Fig. $3 b$ in Wheeler and Kiladis (1999). See main text for more details

of less than about $1 / 30$ cycles per day (cpd) and small zonal wavenumber propagating eastwards. However, this peak in spectral power is slightly less pronounced and slightly more spread in the zonal wavenumber direction than that found from the National-Center for Environmental Prediction-Department of the Environment (NCEP-DOE) Reanalysis 2 (Kanamitsu et al. 2002; not shown here). In the reanalysis the peak ranges from about zonal wavenumber 0 to 2 , and is greatest at 1 ; in the model the peak ranges from close to 0 to about 5 , and is greatest at 2 . Hence, the zonal structure tends to vary too much in the model, and on average the wavenumber tends to be too high. The frequency range covered by the MJO spectral peak is very nearly the same as in the reanalysis, but does extend slightly into higher frequencies (up to around $1 / 25 \mathrm{cpd}$ in the model as opposed to $1 / 30 \mathrm{cpd}$ in the reanalysis).

In Sect. 1 the MJO was described as consisting of convectively-coupled equatorial Kelvin and Rossby waves. Both such waves are present in the OLR power spectrum (relative maxima along the relevant dispersion curves in Fig. 1), which is consistent with the fact that MJO-like variability appears in the model.

The WH04 MJO indices are based on the leading two EOFs of the combined field of OLR, $u_{850}$ and $u_{200}$. As well as being used to define the phases of the MJO, in a model the structure of the EOFs themselves also gives an indication of how realistic the MJO is. Following WH04, the mean and first three harmonics of the annual cycle 
Fig. 2 EOFs of the combined field of OLR, $u_{850}$ and $u_{200}$, from WH04 (a EOF1 and b EOF2) and HiGEM (c EOF2 and $\mathbf{d}$ EOF1). The percentage of the total variance explained by each EOF is printed in the bottom right of the panel. A land mask, generated using the GLOBE topography data set at $0.11^{\circ} \times 0.11^{\circ}$ resolution and covering the same latitude range as was used to generate the EOFs, is shown for information

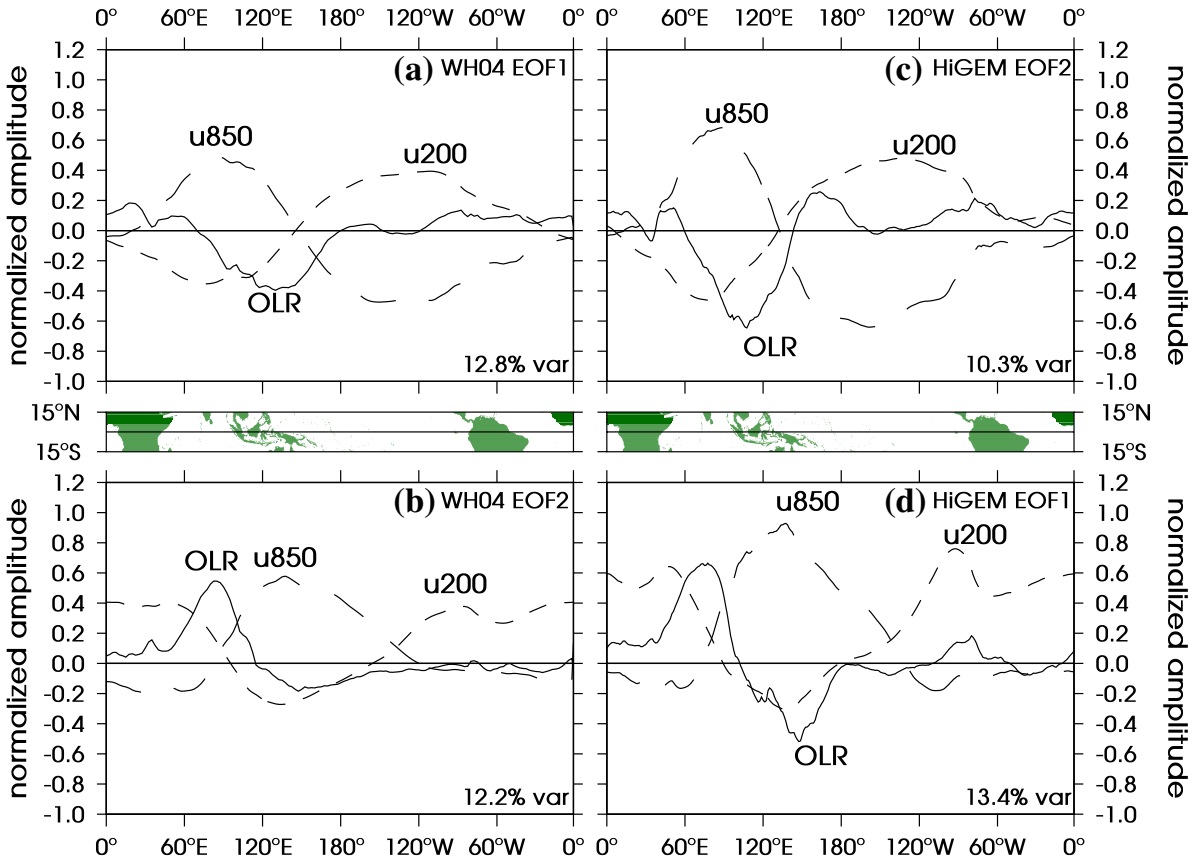

were removed from each grid point for the three fields individually, and the mean of the previous 120 days was then subtracted at each time to remove further unwanted variability. The fields were averaged over the range $15^{\circ} \mathrm{S}-15^{\circ} \mathrm{N}$, non-dimensionalized by normalizing by the standard deviation of each, then concatenated along the longitude axis.

The leading two EOFs of this combined field describe 13.4 and $10.3 \%$ of the total variance each, which is significantly larger than the proportion described by the third $(6.2 \%)$. These EOFs are plotted in Fig. 2d, c respectively. Fig. 2a, b show the first two EOFs, in order, found by WH04 from reanalysis data. WH04's EOF1 and HiGEM's EOF2 exhibit very similar spatial structures, as do WH04's EOF2 and HiGEM's EOF1. The WH04 EOFs account for 12.8 and $12.2 \%$ of the total variance. From North et al. (1982), the error in an eigenvalue $\lambda$ is

$\delta \lambda \sim \lambda \sqrt{\frac{2}{N}}$

where $N$ is the number of independent realizations of the MJO. WH04 used 8401 days of data so, taking a typical MJO period of about 48 days and a decorrelation timescale of one-quarter of a cycle, we let $N=700$. Hence, measured in percent of the total variance,

$\lambda_{1}=(12.8 \pm 0.68) \%$,

$\lambda_{2}=(12.2 \pm 0.65) \%$.

Therefore, the uncertainty ranges of WH04's leading two eigenvalues overlap, so the EOFs are degenerate. Hence, there is no inconsistency between the WH04 EOFs and the HiGEM EOFs, even though they are ordered differently.

The similarity between WH04's EOFs and those generated from HiGEM is remarkable. Nearly all the same local maxima and minima, for all three variables and for both EOFs, are present. The differences which exist are a change in amplitude, or a shift in longitude, of the same features found in the observed EOFs. For example, the chief minimum in OLR in WH04 EOF1 is quite broad and centred around $130^{\circ} \mathrm{E}$, whereas the corresponding minimum in HiGEM EOF2 is sharper and centred around $105^{\circ} \mathrm{E}$. Also, there is only a very shallow minimum in OLR in WH04 EOF2 at around $145^{\circ} \mathrm{E}$, whereas HiGEM EOF1 has a far more pronounced minimum at the same longitude. Overall, however, the longitudinal structure of the MJO in HiGEM is very realistic.

It must be emphasized at this point, however, that WH04 use only one spatial dimension in their EOFs, having averaged over $15^{\circ} \mathrm{S}-15^{\circ} \mathrm{N}$. It is quite possible for errors in the latitudinal structure to be hidden by this averaging. This is of particular concern in the light of the results of Peatman et al. (2014), which demonstrated that in the Maritime Continent region the $\mathrm{MJO}$ convective envelopes are far from homogeneous. Therefore, we also consider composites of daily mean precipitation in each phase of the MJO.

Although we have seen that the EOFs generated from HiGEM match those of WH04 very closely, we proceed by using the WH04 EOFs to allow consistency with other studies. Projecting the combined time series of OLR, $u_{850}$ and $u_{200}$ onto those EOFs allows us to define eight phases, as in WH04's Fig. 7. Anomalies of the daily mean 

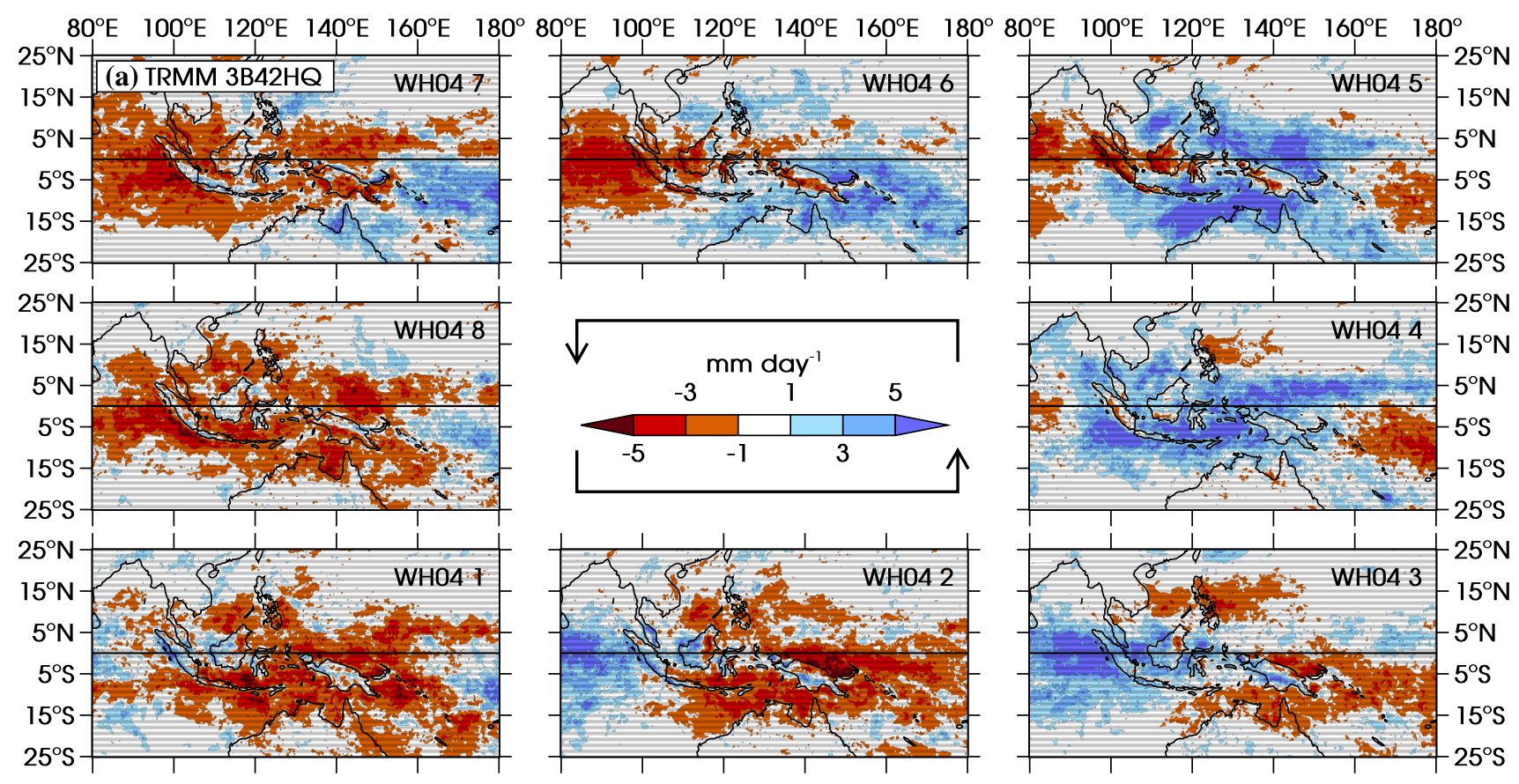

$80^{\circ} \mathrm{E} \quad 100^{\circ} \mathrm{E} \quad 120^{\circ} \mathrm{E} \quad 140^{\circ} \mathrm{E} \quad 160^{\circ} \mathrm{E} \quad 180^{\circ} 80^{\circ} \mathrm{E} \quad 10^{\circ} \mathrm{E} \quad 120^{\circ} \mathrm{E} \quad 140^{\circ} \mathrm{E} \quad 160^{\circ} \mathrm{E} \quad 180^{\circ} 80^{\circ} \mathrm{E} \quad 100^{\circ} \mathrm{E} \quad 120^{\circ} \mathrm{E} \quad 140^{\circ} \mathrm{E} \quad 160^{\circ} \mathrm{E} \quad 180^{\circ}$
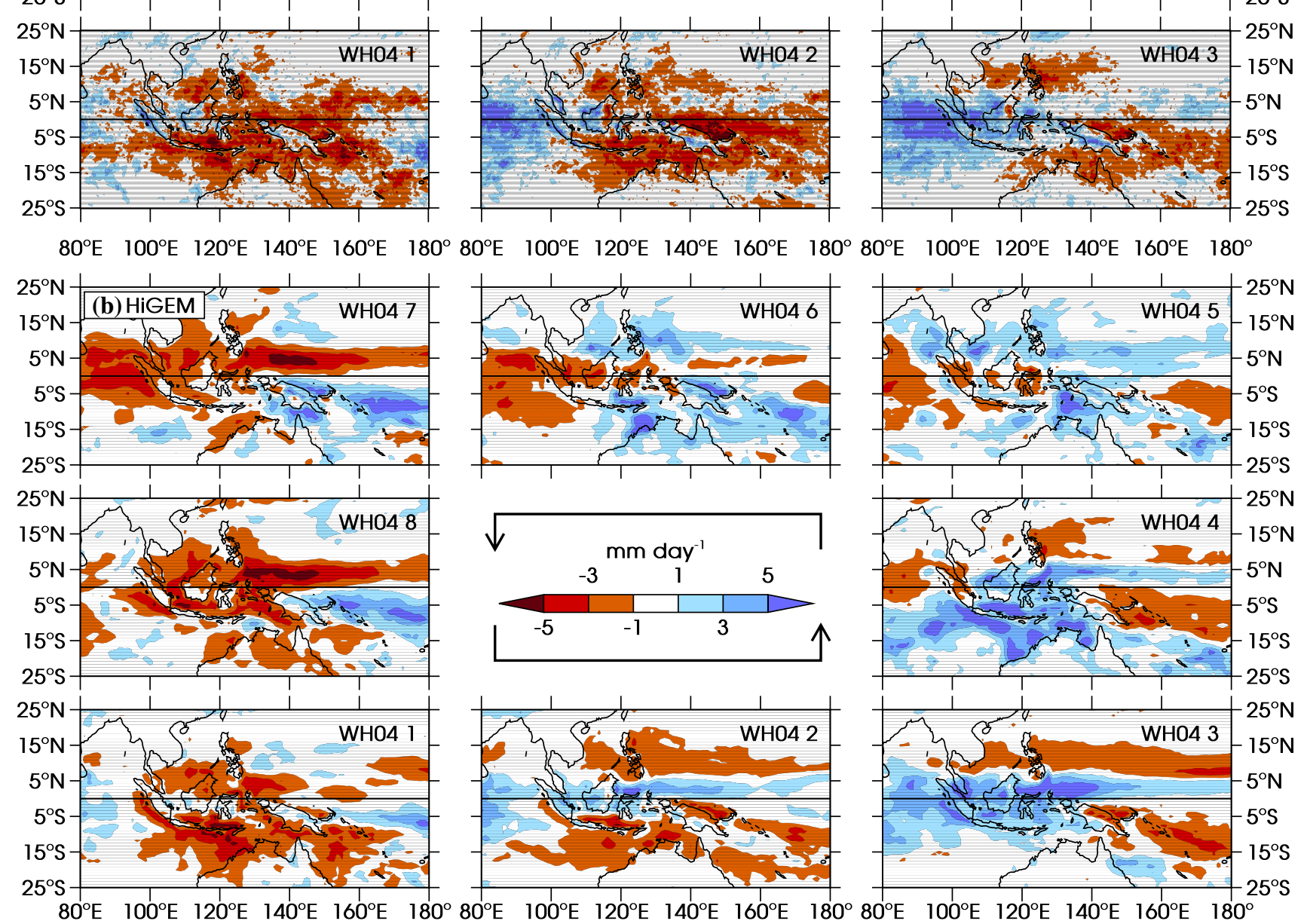

Fig. 3 Anomaly of daily mean precipitation $\bar{r}$ in each phase of the MJO, for a TRMM 3B42HQ and $\mathbf{b}$ HiGEM. Phases move forward in time in the anti-clockwise direction round the diagram

precipitation in each of these phases show alternate positive and negative large-scale envelopes propagating slowly eastwards from the Indian to the Pacific Oceans (Fig. 3b). This behaviour in the model is expected since the phases are defined by projecting onto EOFs which describe just such a propagation in OLR, and OLR is closely related to precipitation.
However, there are some clear errors which become apparent when looking at this two-dimensional field. In phase 1 HiGEM produces a suppressed envelope which has strong negative (dry) anomalies in two regions, north and south of the equator. This bifurcation of the envelope is even clearer in phases 2 to 4 , in which a positive anomaly appears to shoot through from the west between 
Fig. 4 a Number of days and b mean RMM amplitude in each phase of the observed MJO (from WH04). Days in which the RMM amplitude is less than 1 have been excluded from both plots. Red regions which lie entirely within the inner grey circle (186 days) or extend beyond the outer grey circle (238 days) are statistically significant at the $95 \%$ confidence level (two-tailed test). c, $\mathbf{d}$ As (a) and (b) respectively but for HiGEM; the $95 \%$ significance levels in $\mathbf{c}$ are 173 and 224 days
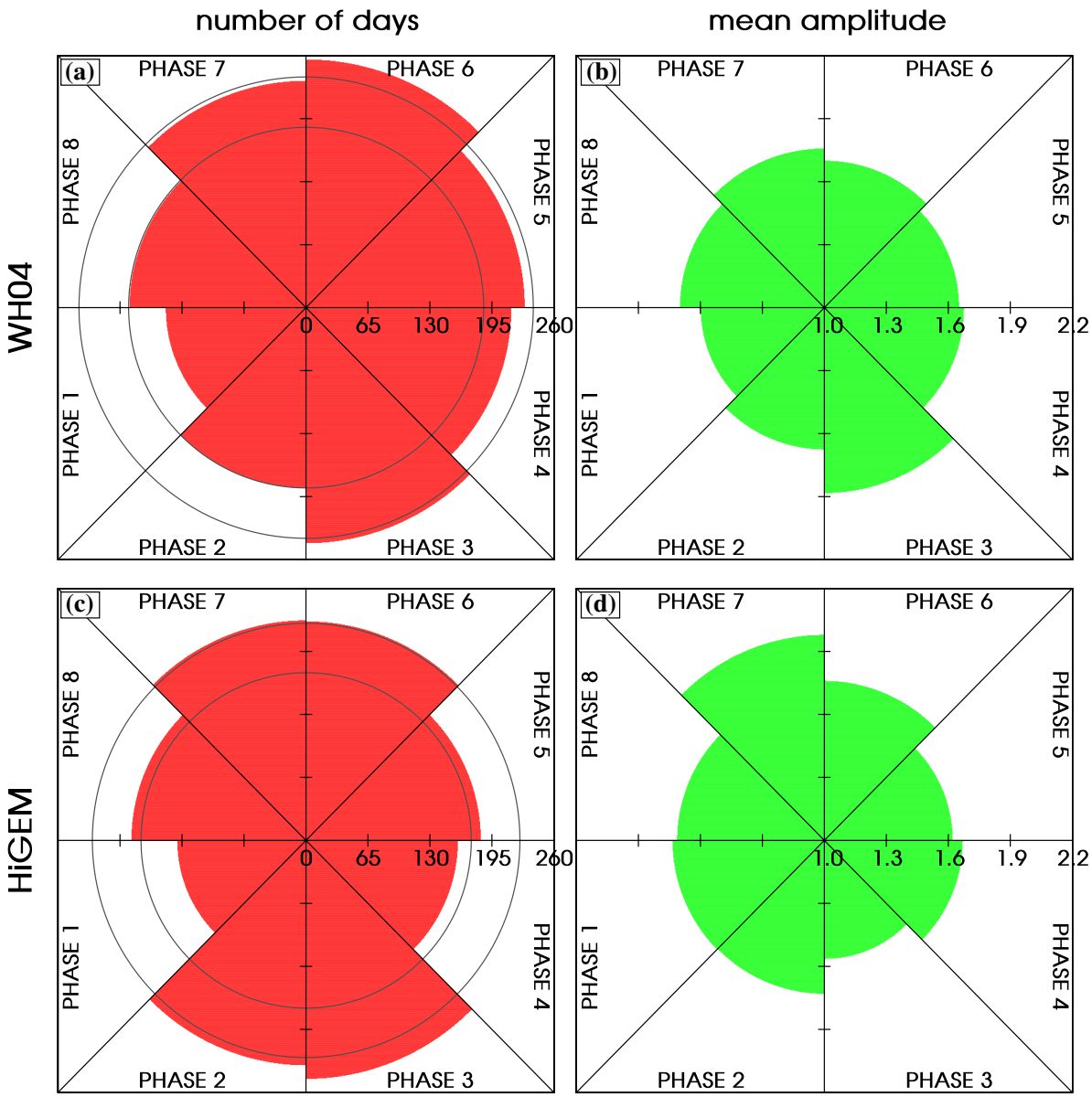

about $0^{\circ}$ and $5^{\circ} \mathrm{N}$. As a result, a persistently strong intertropical convergence zone (ITCZ) occurs whilst the surroundings are in the suppressed MJO phase. It could be argued that this does also occur in observations (Fig. 3a) but the effect is not nearly as clear or prolonged. The manner in which the anomaly in the model appears to move through quickly from the west is consistent with a strong equatorial Kelvin wave. A similar effect occurs but for a sign change in phases $6-8$, with a suppressed anomaly along the ITCZ splitting the active envelope into two.

Peatman et al. (2014) noted gaps, colocated with the Maritime Continent islands, in the MJO envelopes. There is some sign of the same phenomenon in HiGEM, albeit less clearly. For example, over northern New Guinea in phase 1 and southern New Guinea in phase 2 there is a positive anomaly within the suppressed envelope; and in phases 5 and 6 the suppressed anomaly extends beyond the main suppressed envelope to Sumatra, Java, part of Borneo and Sulawesi (phase 5), and to Borneo, Sulawesi and the Bird's Head Peninsula at the north-west corner of New Guinea (phase 6). This "leaping ahead" of the anomaly, and its relationship with the diurnal cycle, will be investigated in Sect. 5.

\section{$4 \mathrm{MJO}$ inertia and propagation}

Figures 1, 2 and 3 are standard diagnostics commonly used in MJO studies. They have shown us that convectivelycoupled intra-seasonal variability around the correct zonal wavenumber does exist in the model (Fig. 1); that the longitudinal structure of the leading modes of OLR, $u_{850}$ and $u_{200}$ are similar to those found in the observed MJO (Fig. 2); and that when projecting data onto these modes and producing composites, we see the active and suppressed envelopes positioned successively further east as expected albeit with some errors, chiefly in the ITCZ (Fig. 3b). In model inter-comparison studies these results would probably satisfy us that HiGEM is one of the more successful models at simulating the MJO, but there are aspects of the MJO which have not yet been investigated at all. For example, although we have composites for each of the eight phases, as yet we have no evidence that these phases occur in succession as they should. Even if the phases do occur in succession, there remains the question of how quickly the model tends to evolve from one phase to the next. Also, when an MJO event occurs (that is, the model moves through successive phases in order), for how many phases does this tend to be sustained before the event 
decays? New diagnostics designed to investigate these aspects of the MJO will now be presented in Sect. 4.1, and their interpretation will be discussed in Sect. 4.2. These diagnostics share some similarities with the MJO activity diagrams of Klingaman and Woolnough (2014a; Fig. 1) and Klingaman and Woolnough (2014b; Fig. 1a, b), but will focus on different aspects of the distribution of MJO phases and the propagation between them.

\subsection{Diagnosis}

Figure $4 \mathrm{a}$ shows the number of days the observed MJO spent in each of the WH04 phases in the study period, and Fig. $4 \mathrm{~b}$ shows the mean RMM amplitude in each of these phases. As ever, for both plots, days on which the RMM amplitude was less than 1 have been excluded. (Note that the axis in Fig. $4 \mathrm{~b}$ begins at 1, not 0 ). If such weak days are included then the number of days in Fig. 4a increases roughly equally for all phases and, of course, the amplitudes in Fig. $4 \mathrm{~b}$ are much smaller for all phases. The equivalent data for HiGEM are plotted in Fig. 4c, d respectively. Given a null hypothesis that the MJO is equally likely to be in any of the eight phases, the grey circles in Fig. 4a, c indicate the 2.5th and 97.5th percentiles (186 and 238 days respectively for the observed $\mathrm{MJO}, 173$ and 224 days for HiGEM). Thus, if the red sector for any given phase does not extend as far as the inner circle then there is a significant tendency against the MJO being in that phase, and if it extends beyond the outer circle then there is a significant tendency for being in that phase.

Although some small variation between the phases is always to be expected, for the observed MJO in Fig. 4a there is a clear difference between the phases with the fewest and the most days. Only 147 days were in phase 1, as opposed to 256 days in phase 6; phase 8 also has significantly few days (and phase 2 has exactly 186 days), and phase 3 has significantly many. In Fig. 4b, phase 3 has by far the largest mean amplitude, and there is very little variation between all of the other phases. For HiGEM the number of days is skewed towards phases 2, 3, 6 and 7 (when the magnitude of RMM2 is larger than that of RMM1), with all of these phases occurring significantly often. There is no such significant pattern for observations, although in both the observations and the model it is phase 1 in which the fewest days fall (135 for HiGEM) and both values are significantly small. The mean amplitude of each phase is roughly similar in the observations and the model but for phase 3 which on average is the strongest in observations (amplitude 1.88) but the weakest in the model (amplitude 1.56).

Having seen the distribution of WH04 phases in the model output we now turn our attention to the propagation of the MJO in RMM space. As explained in Sect. 2.2 the

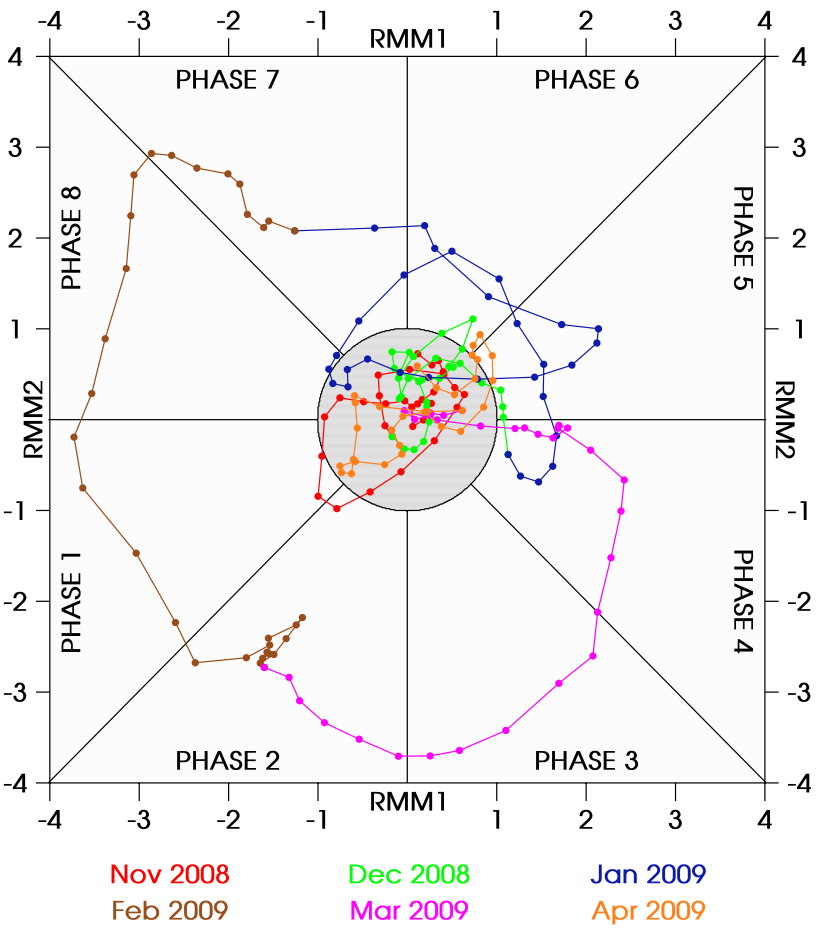

Fig. 5 Wheeler-Hendon phase diagram (see Wheeler and Hendon 2004) for boreal winter 2008-2009 in HiGEM, chosen as an example to show a time of weak MJO (when the RMM amplitude is less than 1 , in the central grey circle) and two propagation events. Propagation occurs from phase 4-8 (first half of January) then from phase 5 right through to 4 (end of January, all of February and most of March)

eight WH04 phases are just octants of the RMM1-RMM2 plane; during an MJO event the MJO can spend several days at a time in one of these phases before propagating into the next octant. However, there are also periods, which may last many weeks, when there is no MJO at all and the RMM amplitude is persistently less than 1 . When an event does occur it does not necessarily begin in phase 1 and end in phase 8. As an example, Fig. 5 shows a WH04 diagram - that is, a plot of RMM2 against RMM1-for the boreal winter 2008-2009 in HiGEM. During most of November and December the MJO is weak (inside the grey unit circle). From 2 January onwards we see anti-clockwise propagation from phase 4 to phase 8 , before the MJO becomes weak again on 15 January; on 22 January the MJO re-emerges in phase 5 and propagates anti-clockwise until it dies on 24 March in phase 4 . Hence, MJO propagation events vary in terms of how far around the phase diagram they travel. They also vary in terms of their rate of propagation through each phase; for example, in the longer propagation event here the MJO spent only 4 days (15-18 February) in phase 1 but 18 days (19 February to 6 March; recall that each month has 30 days in model time) in phase 2 .

In order to study how long the MJO tends to spend in any given phase, for Fig. 6 all instances of the same phase 

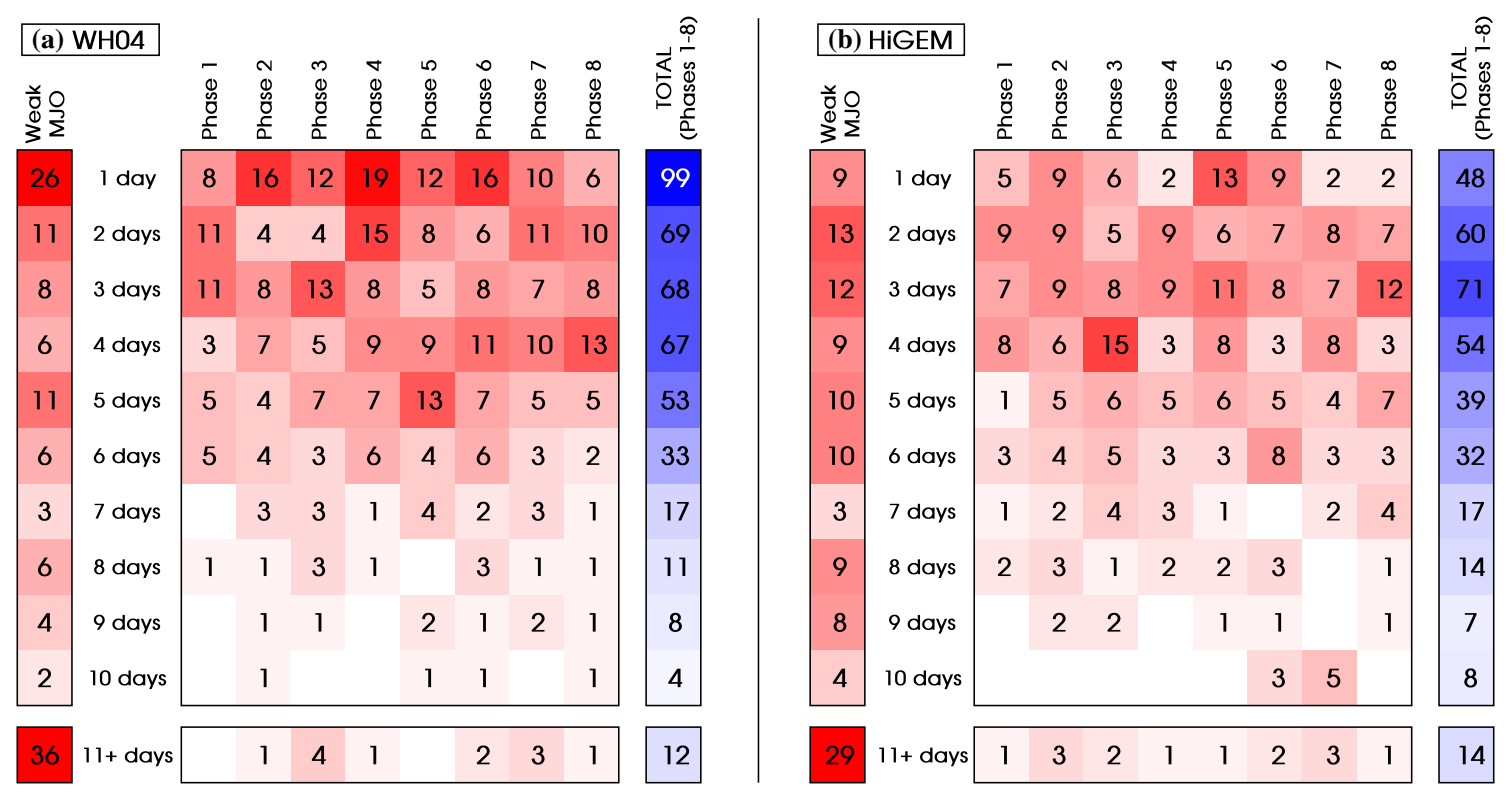

Fig. 6 Histograms showing the number of occurrences of strings of successive days of the same phase, for a the observed MJO (from WH04) and $\mathbf{b}$ HiGEM. For example, in $\mathbf{b}$ there were 15 instances of phase 3 occurring on exactly 4 successive days

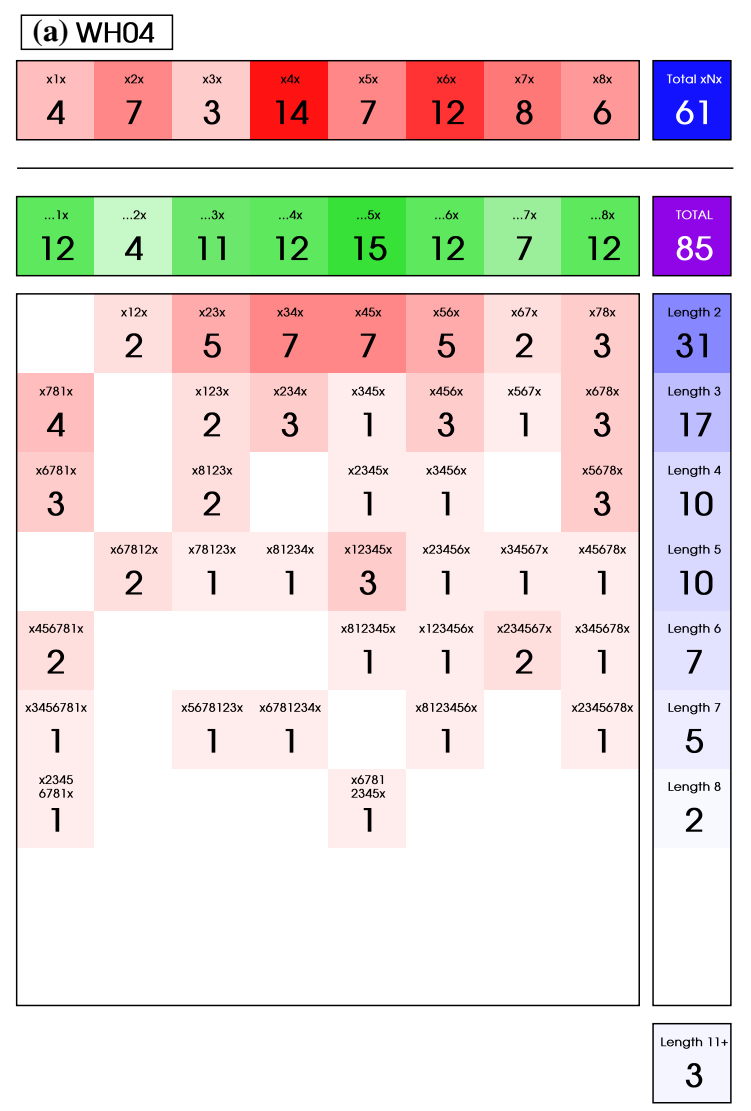

Fig. 7 Histograms of MJO "events", for a the observed MJO (from WH04) and b HiGEM. An $\mathrm{N}$ denotes any phase; an $\mathrm{x}$ denotes any phase that does not continue the numerical sequence; and an ellipsis denotes any sequence of phases. For example, "x $34 x$ " means a phase other than 2 , followed by phase 3 , then phase 4 , then a phase other than $5 ;$ “...3x" means any event of length 2 or more, ending with $3 \mathrm{x}$ (b) HiGEM

\begin{tabular}{|c|c|c|c|c|c|c|c|c|}
\hline$x \mid x$ & $x 2 x$ & $x 3 x$ & $x 4 x$ & $x 5 x$ & $x 6 x$ & $x 7 x$ & $x 8 x$ & Total $x N x$ \\
7 & 9 & 10 & 1 & 7 & 8 & 5 & 7 & 54 \\
\hline
\end{tabular}

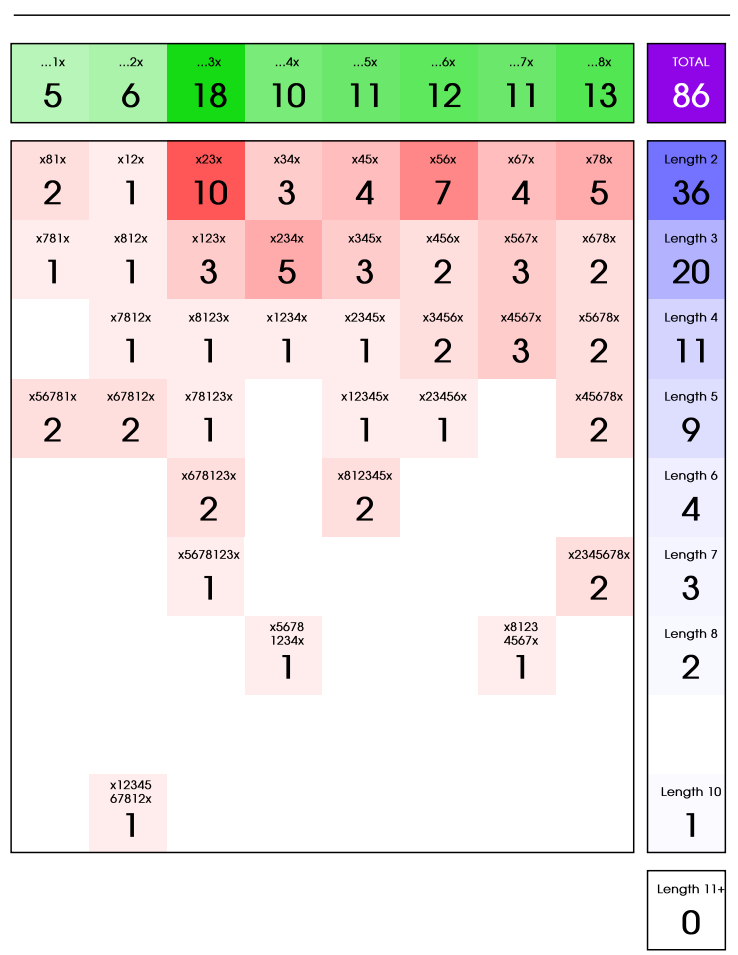

(which could be $\mathrm{x} 23 \mathrm{x}$ or $\mathrm{x} 123 \mathrm{x}$ or $\mathrm{x} 8123 \mathrm{x}$, and so on). The top row shows the number of one-phase events (i.e., no propagation whatsoever). The large red grid shows the number of each type of event; they are summed by end phase (above in green) and by length (to the right in blue). The purple box shows the total number of events of length 2 or more. See main text for full details 
occurring on successive days were found, as were all instances of a phase occurring in isolation (i.e., for just 1 day at a time). Days on which the RMM amplitude was less than 1 had been relabelled as phase " 0 " so do not contribute to these events. The histogram shows the number of times that a string of any given number of successive days were all in the same phase (with phase 0 shown on the left-hand side, labelled "Weak MJO"). For example, to find the number of times that exactly 2 days in a row were in phase 4 in the observed MJO, see the second row of the fourth column in the main grid of Fig. 6a; there were 15 such occasions.

For most phases in Fig. 6a the frequency distribution is skewed towards the top of the histogram, suggesting that the MJO tends to move through the phase quite rapidly. This is especially true of phase 1: on only one occasion was the MJO in that phase for more than 6 successive days, and even then it was for only 8 days. In contrast, the MJO remained in phase 3 for more than 6 successive days on 11 occasions, the longest being 13 (not shown). The total number of events of each length, shown in the blue column on the right of the panel, is monotonically decreasing; the number of 1-day events is considerably higher than the total for any other length. This is in marked contrast to HiGEM's MJO (Fig. 6b). Here, the totals peak at length 3 days, with only 48 1-day events but 713 -day events. Hence, the modelled atmosphere has more "inertia" with respect to the MJO, with a tendency for it to remain in the same phase for a longer period of time than in observations.

Figures 4, 5 and 6 treat WH04 phases in isolation. However, it is obviously crucial that a model is able to simulate the evolution of the MJO from one phase to the next. To diagnose this, a modified technique was used (Fig. 7). Days with an RMM amplitude of less than 1 were again relabelled as being in phase 0 . Then, inspired by the method of Matthews (2008), any duplicate phases on successive days were removed; for example, any number of successive $4 \mathrm{~s}$ would be replaced by a single 4 . All instances were then found of at least two consecutive phases occurring successively. For example, if a 1 is followed by a 2 , or a 5 is followed by a 6 , or an 8 is followed by a 1 , and so on, then there is an MJO "event". It is emphasized that these are not necessarily MJO events in the conventional sense, which are often thought of as a complete cycle through all the WH04 phases. A sizeable proportion of the events in this analysis (36\% for WH04, $42 \%$ for HiGEM) are only two phases long, but even these are of interest because they help us to identify the phases during which the MJO tends to die out. All instances were also found of "standalone" phasesthat is, a phase neither following nor followed by a phase in sequence. Figure 7 shows histograms of these events, for the observed MJO (Fig. 7a) and HiGEM (Fig. 7b). In the notation used in the diagram, a letter $\mathrm{x}$ denotes a phase out of sequence. Thus, an "x345x" event means an instance of phase 3 followed by phase 4 followed by phase 5 , with the whole event preceded by any phase other than 2 and succeeded by any phase other than 6 . (In practice, an $\mathrm{x}$ is usually phase 0 ). In the histograms, events are sorted by their end phase (the phase at which the RMM amplitude decays or the propagation in some other way ceases) and by their length. The red row at the top of the diagram shows the number of times that an MJO-like signal appears but never propagates into the next phase.

The distributions of the observed (Fig. 7a) and modelled MJO (Fig. 7b) are broadly similar. The number of events of length 2 or more (shown in the purple boxes) is almost the same in the two cases, and the distributions of total number of events, in the blue column, are also similar (both are monotonically decreasing with increasing length, at roughly the same rate). This suggests that the number of propagating MJO events is very realistic in the model. In addition, the number of events of length 1 (61 in observations, 54 in HiGEM) and length 2 (31 in observations, 36 in HiGEM) are similar, so the frequency with which nonpropagating MJO-like conditions appear is also realistic.

If we take as a null hypothesis that length-1 events are equally likely to occur for any of the eight phases, in a twotailed statistical significance test with a $95 \%$ confidence interval we reject the null hypothesis-and conclude that there is a bias towards or against an $\mathrm{xNx}$ event occurring for a particular phase-if there are fewer than 3 or more than 13 observed events, or fewer than 2 or more than 11 HiGEM events, for any given phase. Thus, the only phase for which there is statistical significance is phase 4, with 14 $\mathrm{x} 4 \mathrm{x}$ events in observations but only 1 in the model. Hence, in observations there is a significant tendency for OLR and zonal wind patterns which look like phase 4 to appear, not propagating from phase 3 first, and not to propagate into phase 5. In the model there is a significant lack of such occurrences, although it must be remembered that phase 4 has a significant lack of days in the model in the first place (Fig. 4c).

The green rows of data show the frequency with which the MJO was in each of the eight WH04 phases immediately before dying out or switching to some other non-consecutive phase. We take as a null hypothesis that MJO propagation is equally likely to end in any of the eight phases and again use a two-tailed statistical significance test with a $95 \%$ confidence interval; we reject the null hypothesisand conclude that there is a bias towards or against ending in a particular phase-if there are fewer than 5 or more than 16 events. Thus, the only phase for which there is statistical significance in HiGEM is phase 3, since there are 18 examples of "...3x" events. In the "...3x" column in Fig. 7b, 10 of the 18 events were only two phases long, suggesting that the model quite frequently initiates MJO-like convection 
over the Indian Ocean which begins to propagate but never reaches the Maritime Continent (phases 4-5). There is no statistically significant evidence for this occurring in observations (Fig. 7a). In observations there are, however, only 4 events ending in phase 2 , which is statistically significant. Thus, in observations, there is a definite lack of events dying out over the Indian Ocean. In the model, the number of "...2x" events is small, with only 6 such events, so there is a sign of the same effect occurring but not at a statistically significant level.

\subsection{Interpretation}

The diagnostics in Figs. 4, 6, and 7 provide a simple comparison between the propagation of the MJO in a model and in observations. In principle, they could be used as the basis for a propagation skill score. This would not be a measure of forecasting skill (i.e., the model's ability to simulate the evolution of any particular, real MJO event), for which more traditional forecast verification techniques could be employed, but of the general ability to simulate an MJO, for example in climate prediction. However, perhaps even more usefully, they also allow a model developer to understand specific characteristics of the observed MJO cycle and diagnose specific problems in a model.

The analysis of HiGEM here provides a good example of the value of these diagnostics. Let us return to Fig. 4a, c. The number of days in each WH04 phase might vary due to different propagation speeds at different stages of the MJO cycle or because there are isolated days (or a few days in succession) which happen to project strongly onto the EOFs even though they are not part of a propagation event. In the observed MJO (Fig. 4a) there is a clear difference between phases $8-2$, with few days, and 3-7, with many days. Hence, it may be that phases $8-2$ occur relatively quickly or that there are lots of days which look like phases 3-7 but are not part of MJO propagation.

Figures 6a and 7a suggest a combination of these explanations to be true. The histogram showing instances of consecutive days being in the same phase (Fig. 6) is skewed towards the short end of the distribution. This is especially true of phase 1, suggesting that the MJO does indeed move quickly through this phase. The histogram showing instances of propagation (Fig. 7a) has a greater frequency of xNNx events involving phases 3-7 than phases 8-2. Hence, it is relatively common for days like phases 3-7 to exist outside of well established MJO propagation.

In HiGEM we have seen that there is a significant tendency for the amplitude of RMM2 to be greater than that of RMM1 (Fig. 4c), but such a tendency does not exist in observations. This is consistent with the ITCZ error noted in the MJO composites in Fig. 3. As explained in Sect. 3 the strong ITCZ occurring out of phase with the surrounding
MJO conditions causes a feature to emerge in the OLR part of one of the EOFs in HiGEM (Fig. 2d) which is not present in the EOFs computed by WH04. However, since WH04's EOFs were used to generate the RMM time series in the model we find that the model output projects more strongly onto EOF2 (positively for the strong ITCZ, negatively for the suppressed ITCZ), thus skewing the distribution towards phases 2, 3, 6 and 7, and away from phases 4, 5,8 and 1 .

We have also seen that the MJO inertia in HiGEM is greater than in observations. That is, the MJO tends to stay in the same phase for longer in the model than in the observations. This is a valuable piece of information for the model developer who wishes to investigate the propagation mechanism in the model in detail. The inertia being too large may indicate that the modelled atmosphere responds too slowly to the forcings which cause the model to move to the next MJO phase. Alternatively, it may be that once an MJO-like signal emerges it becomes too robust, and is less susceptible to decay than in observations. Thus, the diagnostic points towards specific processes in the model which require further examination and development.

For HiGEM the histogram of propagation events (Fig. 7b) showed significantly many events ending in phase 3, but there is no evidence for such an effect in observations. This appears to be a key feature of the modelled MJO, which may also contribute to there being so few days in phase 4 (Fig. 4c) because the MJO tends to die out before reaching it. The fact that the model tends to have a dying MJO in phase 3 is presumably due to the average amplitude in that phase being so weak (Fig. 4d). Why this amplitude is so weak is not clear, and warrants further investigation. Indeed, the fact that the same phase has by far the strongest amplitude in observations suggests that there is a particularly serious systematic bias present. Further investigation is needed to identify the source of the error. The cause of the strength of phase 3 in the observed MJO is also unclear.

It has been shown that the new diagnostics presented here are useful in diagnosing strengths and weaknesses in the simulation of the MJO cycle in HiGEM, that they can tell us specifically about the nature of the propagation (or otherwise) through the MJO phases, and that they can inform further model development by contributing to the identification of the sources of errors.

\section{Scale interaction with the diurnal cycle}

The Maritime Continent is the land area over which the MJO has the greatest influence on precipitation. It is home to around $5 \%$ of the human population and the significant latent heat release associated with deep convection there has led to it being termed the "boiler box" for 
the atmosphere. Hence, there are major human and scientific needs for precipitation to be modelled accurately over the Maritime Continent, and the results of Peatman et al. (2014) indicate that this requires the scale interaction between the MJO and diurnal cycle to be simulated correctly. This interaction will now be diagnosed in HiGEM.

\subsection{Diurnal cycle and its modulation}

We have seen that HiGEM, but for some systematic errors as described in Sects. 3 and 4, has a very realistic MJO. We must now establish whether the climatological diurnal cycle is also accurate. The precipitation field was output every three hours and, as described in Peatman et al. (2014), the data were converted by linear interpolation to 00:00, 03:00, ..., 21:00 local solar time (LST) at each longitude. Composites were created for each LST time step and the diurnal harmonic was found at each grid point. Thus, the diurnal cycle is modelled as being sinusoidal, and is described at each grid point by two values: the amplitude $\left(r_{d}\right)$ and phase $\left(\phi_{d}\right)$.

The spatial extent of the region with $r_{d}>3 \mathrm{~mm} \mathrm{day}^{-1}$ in HiGEM is reasonably accurate (Fig. 8). The largest amplitude is over land, and the diurnal cycle over ocean is weak (generally $3-6 \mathrm{~mm} \mathrm{day}^{-1}$ ) close to the islands and even smaller a long way from it. However, there are differences between the model and observations, as illustrated by Fig. $8 \mathrm{c}$ which shows the model bias. $r_{d}$ in the model is broadly homogeneous over land regions whereas in reality there are substantial regional variations. This causes many of the large islands to have regions of both positive and negative bias. HiGEM's diurnal cycle is systematically weak over regions where it does not resolve high orography (e.g., south-west Sumatra, Java and central New Guinea) and where it fails to simulate nocturnal offshore propagation (e.g., off the south-west coast of Sumatra, north-west coast of Borneo and north coast of New Guinea), and tends to be slightly too strong over the seas of the Maritime Continent.

Maps of the diurnal phase $\phi_{d}$ (Fig. 9) contain major biases. In the observed diurnal cycle the land is almost clear of precipitation thoughout the morning (see Peatman et al. 2014), with precipitation starting around the edges of the islands during the afternoon, and strengthening and spreading inland throughout the afternoon and evening (Fig. 9a). In contrast, in HiGEM the precipitation over the land tends to peak in the middle of the day (Fig. 9b); the phase appears to be locked to that of the incoming solar radiation. An early phase has been reported in the tropical diurnal cycle of many climate models (e.g., Collier and Bowman 2004; Slingo et al. 2004; Wang et al. 2007; Hara et al. 2009). In the UK Met Office model, over the Maritime Continent, this systematic bias remains until the model is

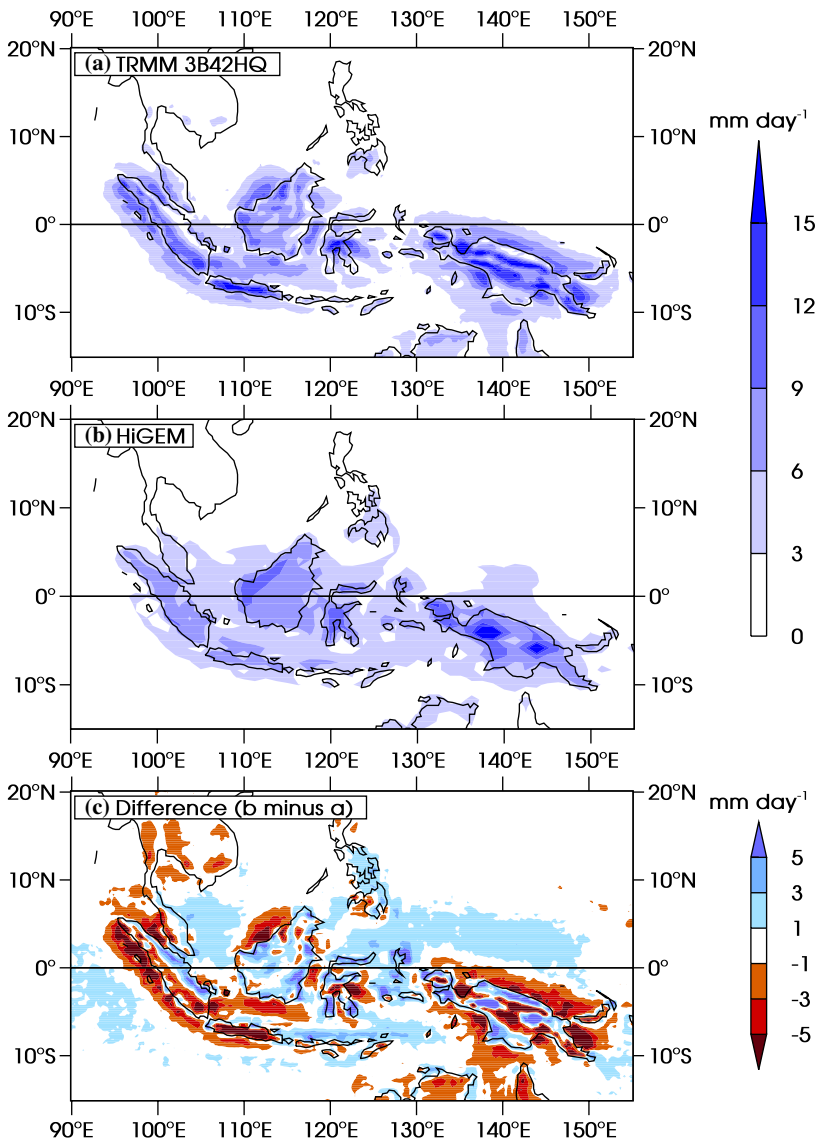

Fig. 8 Amplitude $r_{d}$ of the diurnal cycle of precipitation, for a TRMM 3B42HQ and b HiGEM. $\mathbf{c} r_{d}$ bias in HiGEM (b minus a)

run at a much higher resolution than HiGEM, such that the convection can be simulated explicitly (Love et al. 2011). In HiGEM, $\phi_{d}$ over land is earliest around the coasts, at about 09:00, and further inland is later, mostly peaking between 12:00 and 15:00. This seems to suggest that the model correctly simulates the initiation of the diurnal cycle as starting at the coasts and moving inland. However, the composites for each time of day (not shown) indicate that this is not the case. Rather, the precipitation is initiated almost homogeneously over the land at about 09:00, and the change in phase between the coasts and inland regions arises from the variation in persistence time of the rainfall. Inland and especially over orography, where the diurnal harmonic peaks latest in the day, the convection begins just as early as on the coasts but lasts many hours longer.

We now investigate whether the diurnal cycle is modulated by the MJO, and whether any modulation is similar to that seen in observations. The diurnal cycle was composited separately for each WH04 phase and the diurnal harmonic was found at each grid point, as above. The anomaly of $r_{d}$ was found for each phase by subtracting the mean over all eight phases, as in Fig. 7 of Peatman et al. (2014). These 


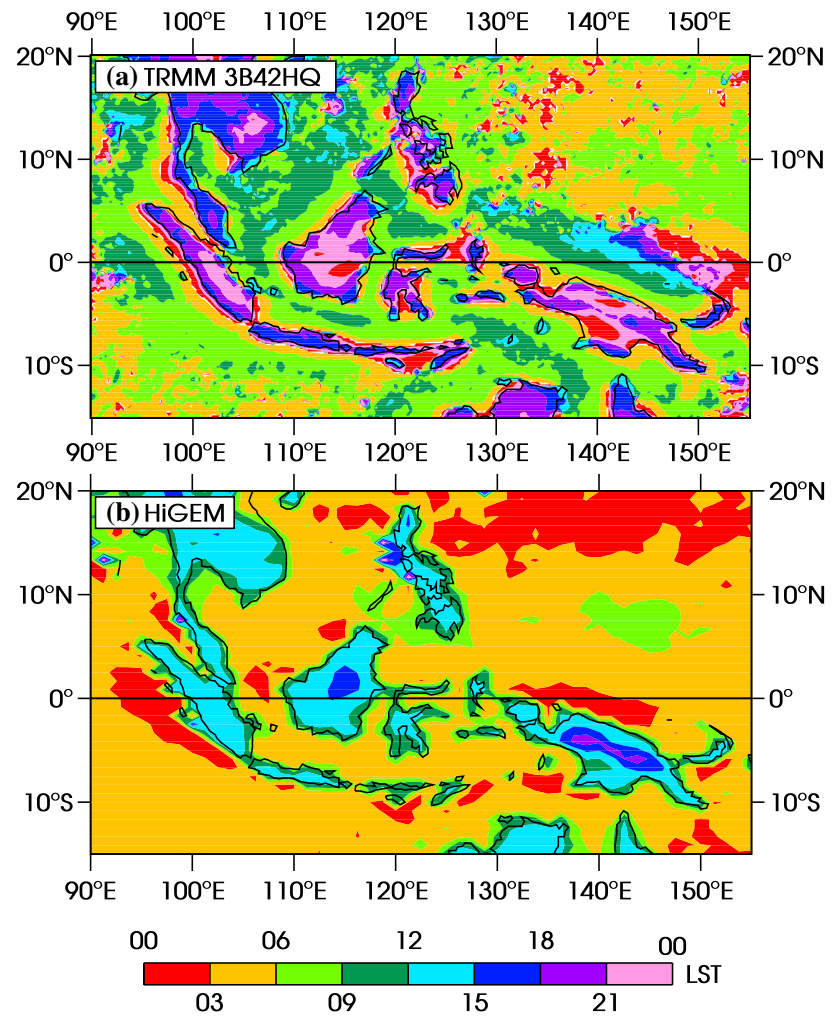

Fig. 9 Phase $\phi_{d}$ of the diurnal cycle of precipitation, for a TRMM 3B42HQ and b HiGEM

anomalies (not shown) tend to have the correct sign but are generally 2 or 3 times weaker than in 3B42HQ observations. However, we have just seen that the climatological amplitude in the model is weaker anyway so we now consider the anomaly of the diurnal amplitude as a percentage of climatology at each grid point (Fig. 10). In order to focus on regions where there is an appreciable diurnal cycle, regions where the climatological amplitude is weak $\left(r_{d}<3 \mathrm{~mm} \mathrm{day}{ }^{-1}\right)$ are masked out in grey. The mean of the absolute value of the percentage anomaly is shown in the bottom-left corner of each panel. The mean of these values is $30 \%$ for 3B42HQ (Fig. 10a) and $18 \%$ for HiGEM (Fig. 10b). Thus, even when normalized by the climatological amplitude the model has a considerably weaker MJOmodulation of the diurnal cycle than exists in observations. However, there is a coherent structure to the regions of enhanced and suppressed $r_{d}$ in HiGEM so the modulation of the diurnal amplitude in the model, despite being weak, is consistent. Similarities and differences between the model and observations are emphasized by Fig. 10c, which shows the meridional average of the percentage anomalies above, for TRMM (thin line) and HiGEM (thick line).

In Fig. 10a there are many localized effects so the $r_{d}$ anomaly is quite noisy. In Fig. 10b, however, there is greater spatial coherence, suggesting that the convective parameterization scheme in the model responds to the MJO in a relatively consistent manner rather than being sensitive to location. In both 3B42HQ and HiGEM there is no clear relationship between orography and the modulation of the diurnal cycle.

In many locations the anomaly is of the same sign in observations and the model in any given WHO4 phase; this is made especially clear by the meridional means in Fig. 10c. The main exceptions are over New Guinea in phases 6 and 7 (where the simulated diurnal cycle is enhanced but the observed diurnal cycle is suppressed); and Sumatra in phases 1 and 5 (where the signs of the anomalies disagree), and phase 2 (where the enhancement of the TRMM diurnal cycle is strong but there is very little modulation in HiGEM). The percentages printed in the bottom-left corner in (a) and (b) are very weakly correlated between 3B42HQ and HiGEM $(R=0.25)$ so there is little or no skill in simulating the varying strength of the diurnal cycle's modulation through the MJO cycle.

\subsection{Relative MJO phases}

We now compare the MJO signals of OLR, daily mean precipitation $\bar{r}$ and diurnal amplitude of precipitation $r_{d}$ over both land and ocean. Figure 11 shows the means over the region $7^{\circ} \mathrm{S}-10^{\circ} \mathrm{N}, 100^{\circ}-120^{\circ} \mathrm{E}$ (parts of Sumatra and the Malay Peninsula, Java and Borneo), for observations (Fig. 11a) and HiGEM (Fig. 11b). The OLR signals in HiGEM are similar to those of brightness temperature $\left(T_{b}\right)$ used in observations, peaking in phase 4 , as expected since OLR is used to define the WH04 phases themselves. (Note that the $T_{b}$ and OLR axes are inverted since lower values correspond to more active convection).

In Peatman et al. (2014) it was shown that over regions where the diurnal cycle is strong it explains $81 \%$ of the variance in $\mathrm{MJO}$ precipitation; the equivalent figure in HiGEM is only $51 \%$. In observations this provided evidence that the strong diurnal cycle over the land of the Maritime Continent is in a 1:1 relationship with $\bar{r}$, so that the spatial structure of the MJO is determined chiefly by the diurnal cycle itself. Furthermore, the diurnal cycle was being triggered ahead of the advancing MJO envelope. Over land (although not over ocean) this was strong enough to cause the daily mean signal over the islands also to "leap ahead" of the main envelope. In HiGEM the evidence suggests that the diurnal cycle does not determine the structure of the MJO, with $49 \%$ of the MJO variability arising from other, presumably more persistent, weather systems. Despite this, the "leaping ahead" of the precpitation signal does still occur in the model.

In observations $r_{d}$ (Fig. 11a, short-dashed lines) peaks in phase 3 over both land and ocean, ahead of the largescale $T_{b}$ envelope in phase 4 . This is also true of HiGEM 

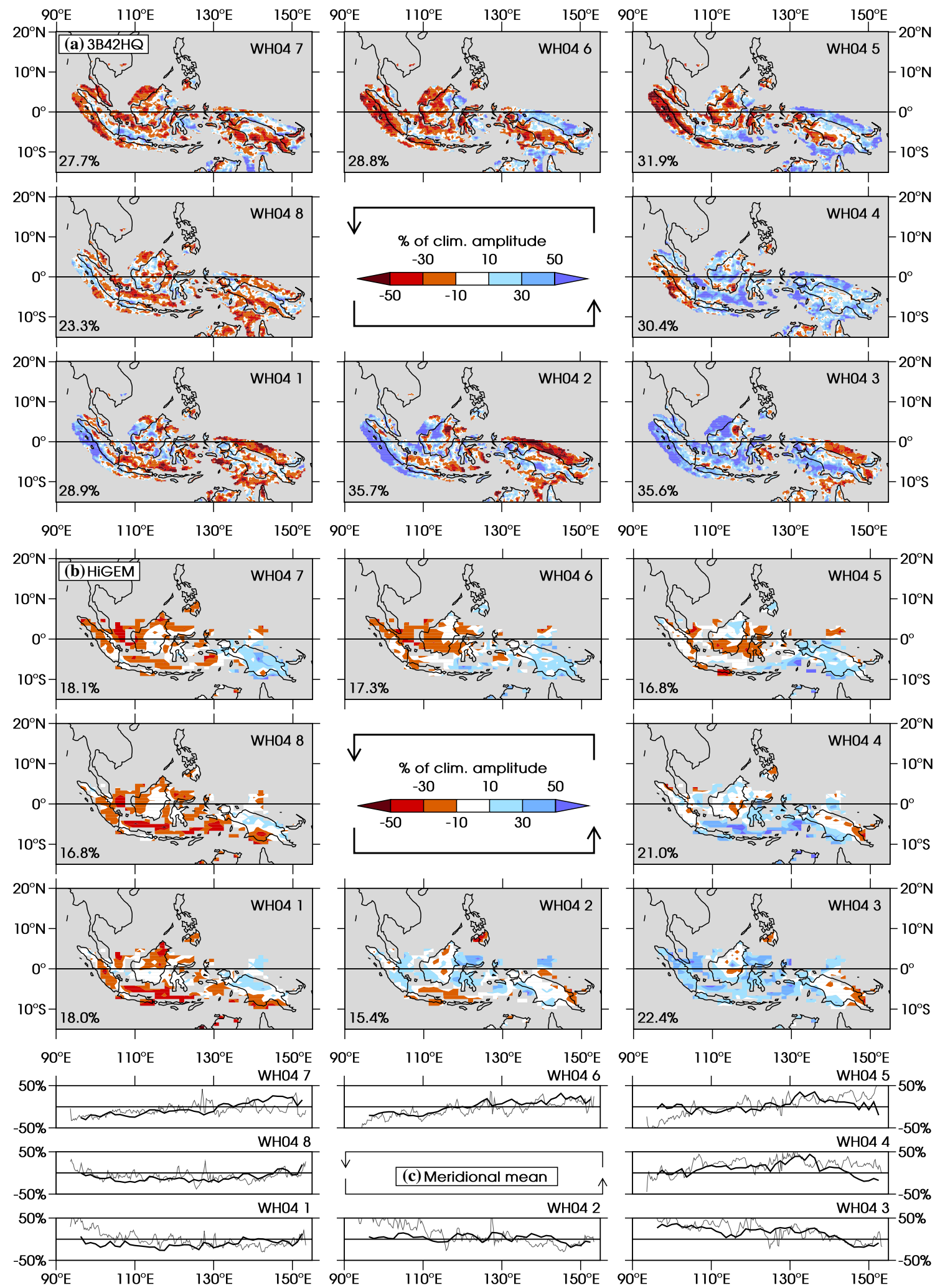

Fig. 10 Anomaly of the amplitude $r_{d}$ of the diurnal harmonic of precipitation in each phase of the MJO, as a percentage of the climatological amplitude: a TRMM 3B42HQ and b HiGEM. Regions where the climatological $r_{d}$ is less than $3 \mathrm{~mm}_{\text {day }}{ }^{-1}$ are masked out in grey. The figure in the bottom-left corner of each panel is the mean of the absolute value for that panel. c Meridional means of non-masked areas for TRMM (thin line) and HiGEM (thick line) 


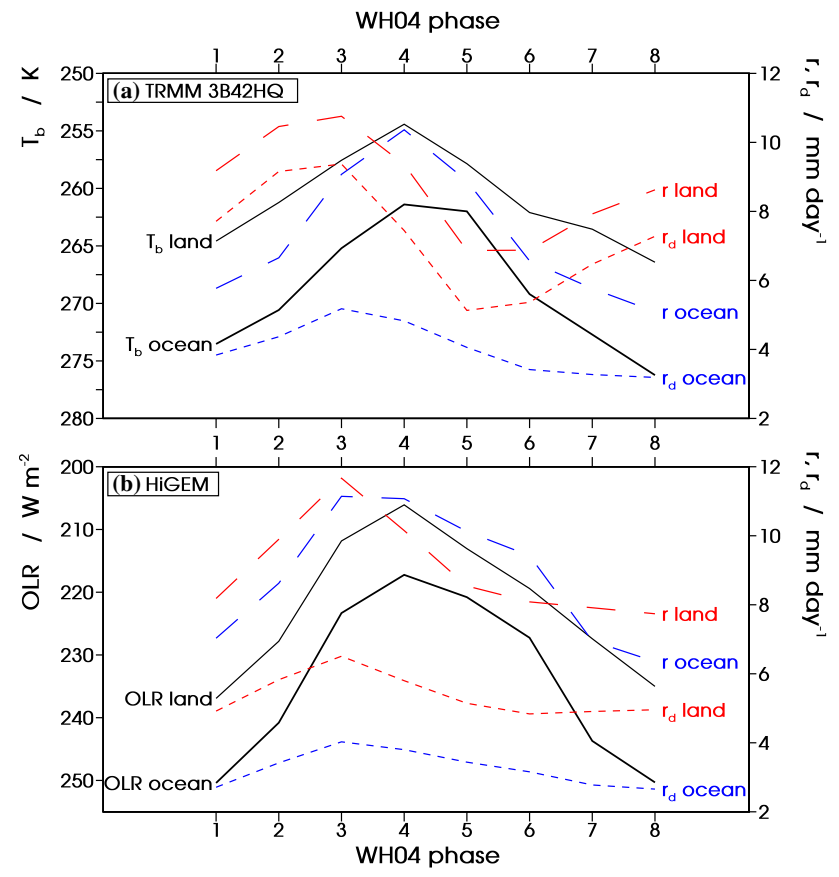

Fig. 11 Daily mean brightness temperature or OLR, daily mean precipitation $(\bar{r})$ and amplitude of the diurnal harmonic of precipitation $\left(r_{d}\right)$, for a observations and b HiGEM, averaged separately over land and ocean for the domain $7^{\circ} \mathrm{S}-10^{\circ} \mathrm{N}, 100^{\circ}-120^{\circ} \mathrm{E}$ (Borneo and most of Sumatra). Note that the brightness temperature and OLR axes are inverted

(Fig. 11b). In observations over land the diurnal cycle is strong enough to cause $\bar{r}$ to peak in phase 3 also, whereas over ocean it peaks in phase with the large-scale envelope in phase 4. Even though we have established in the model that the same relationship does not exist between $\bar{r}$ and $r_{d}$, the daily mean precipitation in HiGEM does peak in phase 3 over land, ahead of the large-scale envelope. Moreover, the same is true over ocean. Hence, the convective parameterization scheme in HiGEM does not cause the scale interaction between the diurnal cycle and the MJO to be modelled correctly, but it is still able to make the rainfall leap ahead of the MJO OLR envelope.

Having compared the large-scale conditions over land and ocean we now compare the timing of OLR and precipitation at each grid point using MJO harmonics (introduced in Sect 4.2 of Peatman et al. 2014). Just as the diurnal harmonic was computed by fitting a sine wave through the eight time steps of precipitation data, so we fit a sine wave through the eight MJO phase composites of any variable to compute its MJO harmonic. The phase lags (measured in WH04 phases) (a) $\Delta \phi\left(-T_{b}, \bar{r}\right)$ (that is, the phase of $\bar{r}$ minus the phase of $\left.-T_{b}\right)$ and (b) $\Delta \phi\left(-T_{b}, r_{d}\right)$ for observations, and (c) $\Delta \phi(-\mathrm{OLR}, \bar{r})$ and (d) $\Delta \phi\left(-\mathrm{OLR}, r_{d}\right)$ for HiGEM, are shown in Fig. 12. The negative of $T_{b}$ and OLR are used since negative anomalies correspond to active convection.
Compared with observations, the phase lags in the model are broadly accurate; they are of the correct sign throughout almost all of the domain, and are of approximately the correct magnitude. In panels (a) and (c) the daily mean rainfall over the land leads the $-T_{b}$ signal by $0.5-1.5$ phases in observations and leads the OLR signal by $0.5-2.5$ phases in the model. The main difference is over Sumatra, where the lag is about 1 phase in observations but about 2 phases in HiGEM.

The other clear difference is over ocean: in observations the precipitation is roughly synchronous with $T_{b}$ but in HiGEM a lag exists just as over the land, especially north of the equator within the Maritime Continent (the ITCZ region). In panel (d), as in observations in panel (b), the $\Delta \phi\left(-\mathrm{OLR}, r_{d}\right)$ signal is generally quite noisy, but there are still clear similarities between HiGEM and 3B42HQ. Over ocean within the Maritime Continent itself the diurnal amplitude is consistently ahead of the OLR, as was the case in observations, and over land it peaks ahead of OLR in general but there is a considerable amount of local variability, and this variability does not agree with that in observations. However, it is a priori unlikely that a global model, unable to resolve all of the coastal and orographic features of the Maritime Continent, would ever simulate a quantity such as this MJO phase lag accurately on small scales. Therefore, the fact that the overall picture of Fig. 12d shows the correct characteristics should be considered a success for the model.

\section{Summary and discussion}

The aim of this paper was to investigate the realism of the MJO in HiGEM, a high-resolution model based on the Met Office Hadley Centre's HadGEM1. Despite the importance of the MJO, it is frequently simulated poorly by climate models with common errors including a lack of eastwardpropagating variability on intra-seasonal time scales, an MJO with an incorrect spatial distribution of convection and a failure to couple convection to the atmospheric dynamics. The main causes of these errors include unrealistic convective parameterization schemes and coarse model resolutions.

MJO-like variability (eastward-propagating with frequency below around 1/30 cycles per day) was shown to exist in HiGEM over a larger range of zonal wavenumbers than in reanalysis data, implying an inconsistent zonal scale to the MJO's OLR envelopes (Fig. 1). However, by the standards of current state-of-the-art GCMs the MJO signal is impressive. The structures of the EOFs of the combined field of OLR, $u_{850}$ and $u_{200}$ in HiGEM are also very accurate. The leading two EOFs are ordered differently from those of WH04, but WH04's EOF1 and EOF2 


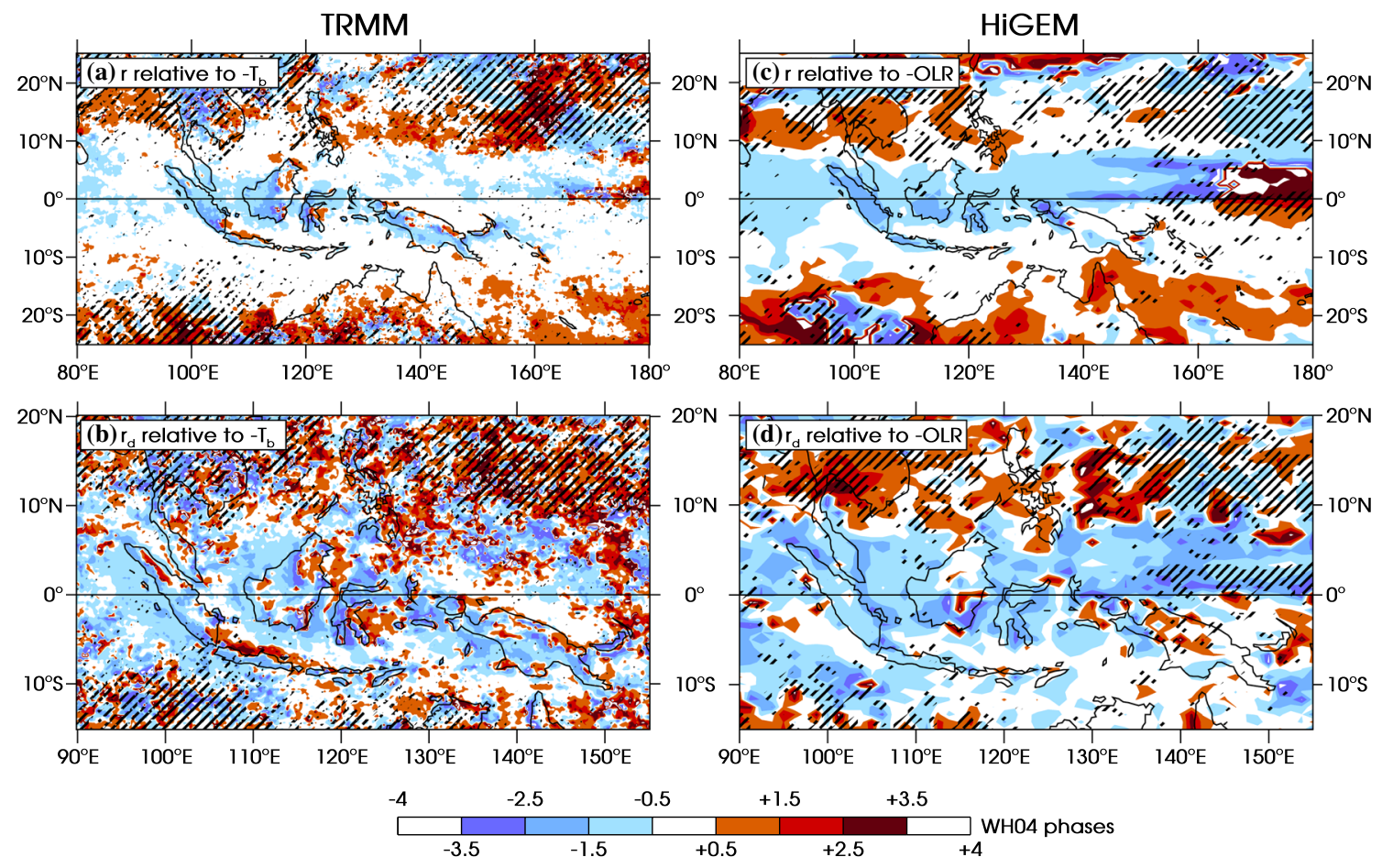

Fig. 12 MJO phase lags from a, b TRMM observations and c, d HiGEM (see main text for details): a $\Delta \phi\left(-T_{b}, \bar{r}\right), \mathbf{b} \Delta \phi\left(-T_{b}, r_{d}\right)$, c $\Delta \phi(-\mathrm{OLR}, \bar{r})$ and $\mathbf{d} \Delta \phi\left(-\mathrm{OLR}, r_{d}\right)$. The scale is measured in MJO phases as defined by WH04. If $\Delta \phi\left(-\bar{T}_{b}, \bar{r}\right)$ is positive (negative) then the maximum in $\bar{r}$ lags (leads) the maximum in $-\bar{T}_{b}$, and similarly for

are degenerate (Eqs. 2a and 2b) so it is consistent for the leading two EOFs in a model to match those of WH04 in either order. The only clear difference between the WH04 and HiGEM EOFs is the existence of a fairly deep trough in the OLR part of HiGEM's EOF1 over the eastern Maritime Continent; the equivalent trough in the WH04 EOF2 is very shallow. This error was shown by composites of daily mean precipitation for each MJO phase (Fig. 3) to be due to the ITCZ peaking strongly in the wrong phase. This also acts to split the MJO's active and suppressed envelopes into two, interrupting the MJO structure considerably. Aside from this one bias, however, the horizontal structure of the MJO envelopes is again very accurate. The ITCZ error is also responsible for the number of days in each phase being skewed towards phases 2, 3, 6 and 7 (Fig. 4c), since projecting the strong ITCZ onto the WH04 EOFs, in which the feature is absent, often results in $|\mathrm{RMM} 2|>|\mathrm{RMM} 1|$. Thus, the bias in the timing of the enhancement and suppression of the ITCZ appears to be responsible for many of the errors seen in the MJO. This is encouraging in the sense that an improvement to the model in this one respect could also improve many other aspects of the MJO's representation.

The histogram showing the frequency of MJO propagation events (Fig. 7b) indicates that the distribution of other phase lags. Black hatching indicates regions of low variability of the diurnal cycle during the MJO, defined as the MJO anomaly of $r_{d}$ being below $1 \mathrm{~mm} \mathrm{day}^{-1}$ (TRMM) or $0.4 \mathrm{~mm} \mathrm{day}^{-1}$ (HiGEM) for all eight WH04 phases

events by length is very accurate indeed. There is, however, a tendency in the model for propagation to cease in phase 3, which is consistent with the fact that the mean amplitude is weak in phase 3 (Fig. 4d). In observations, phase 3 is on average the strongest. The observed MJO has a significant tendency not to die out in phase 2 (Fig. 7a), whereas the model has no such significant tendency. Also, the MJO "inertia" in the model is too great, with the MJO most likely to spend 3 successive days in the same phase, whereas in observations it is most likely to spend only 1 day in each phase at a time. The reasons for the strong phase 3 and the robustness of the propagation through phase 2 in observations, and the weak phase 3 and the high MJO inertia in the model, are unknown and warrant further investigation.

The diurnal cycle of precipitation over the Maritime Continent has an accurate spatial structure but for the fact that its amplitude over land is systematically too weak (Fig. 8b), but the diurnal phase (Fig. 9) is roughly simultaneous with solar heating. The latter is due to errors in the convective parameterization scheme and occurs in very many models of the tropical diurnal cycle. It is likely that such a bias has knock-on effects since it results in too many clouds in the middle of the day, and therefore too high an albedo when insolation is strongest. 
Peatman et al. (2014) reported a considerable modulation of the observed diurnal amplitude $r_{d}$ by the MJO. There is also a modulation in HiGEM (Fig. 10), generally of the correct sign, but it is too weak (even when normalizing by the climatological $r_{d}$; the average modulation is $30 \%$ in 3B42HQ but only $18 \%$ in HiGEM) and the relative strengths of the modulation in each phase are inconsistent with observations. The weakness of the diurnal amplitude, the earliness of the diurnal phase and the weakness of the $r_{d}$ modulation may all be indicative of an inability of the convective parameterization scheme to couple properly to dynamics. It is quite possible, therefore, that the weakness of the climatological diurnal cycle and the weakness of its modulation by the MJO are two manifestations of the same model error, especially given that the sign of the modulation tends to be correct.

In Fig. 11a the observed diurnal cycle was shown to peak ahead of the advancing MJO envelope over both land and ocean, with the land-based cycle strong enough to make the daily mean precipitation signal also "leap ahead" of $-T_{b}$ in the MJO. In HiGEM the diurnal cycle also leaps ahead of the MJO (Fig. 11b) but is not strong enough to determine the daily mean signal, with only $51 \%$ of the MJO variability in $\bar{r}$ being attributable to changes in $r_{d}$ (the equivalent figure for observations is $81 \%$ ). However, the daily mean signals over both land and ocean do leap ahead of the MJO, suggesting that not only the diurnal cycle but also other (presumably more persistent) weather systems peak ahead of the advancing MJO envelope.

The relationships between OLR, $\bar{r}$ and $r_{d}$ at each grid point were compared using the difference in phase between their MJO harmonics (Fig. 12). In observations the daily mean precipitation was out of phase with $-T_{b}$ over land, but in the model the same is true over the ocean also. Over Sumatra, the MJO phase lag is $2 \mathrm{WHO} 4$ phases (that is, $\bar{r}$ peaks a quarter of an MJO cycle ahead of the most active OLR), so OLR acts as an even worse proxy for rainfall over that location. Overall, however, the phase lag is reasonable, both for $\bar{r}$ and $r_{d}$. Thus, one aspect of the convection scheme is very accurate- the strongest OLR signal does not coincide with the heaviest precipitation.

When analysing skill at modelling the MJO it is common, especially in model inter-comparison studies, to use a relatively narrow range of diagnostics such as wavenumberfrequency spectra, ratios of eastward- to westward-propagating spectral power and EOFs. These have the disadvantages that they tend to involve averaging over a latitude band rather than considering the whole horizontal structure, neglect to examine the episodic nature of the MJO, and do not consider the complex interactions between the MJO and other systems such as the diurnal cycle. Such considerations are all crucial to the distribution of convection and, therefore, latent heat release associated with the MJO. This study has shown the value of more detailed diagnostics, the like of which we contend should be used in any comprehensive analysis of the MJO in a model. The simpler diagnostics mentioned above are very useful for inter-comparison projects in which it is desirable to compute a series of quantities which provide an easy comparison between many models, but it is important not to think of these as the last word in MJO diagnosis.

Novel diagnostics presented in this paper have exposed very specific issues with the HiGEM's simulation of the MJO, which can ultimately be used to guide future model development. In particular, examining the frequency of occurrence of each MJO phase, the MJO inertia and the frequency with which propagation occurs has highlighted successes and failures in HiGEM's treatment of each stage of the MJO cycle. Furthermore, the examination of the scale interaction with the Maritime Continent diurnal cycle was necessary to evaluate the spatio-temporal distribution over one of the wettest and most highly populated regions of the planet. We propose that studies of the MJO in climate models should always take such diagnostics into account.

Acknowledgments GLOBE topography data were downloaded from the web site of the NOAA-NGDC (http://www.ngdc.noaa.gov/ mgg/topo); TRMM 3B42HQ precipitation data from NASA-Goddard (http://mirador.gsfc.nasa.gov); and WH04 EOFs from the Centre for Australian Weather and Climate Research (http://www.cawcr.gov.au/ staff/mwheeler/maproom). SCP was supported by a NERC PhD studentship (grant number NE/I528285/1). The research presented in this article was carried out on the High Performance Computing Cluster supported by the Research Computing Service at the University of East Anglia. The authors are grateful to Dr Cathryn Birch for useful feedback on this paper, and two anonymous reviewers whose comments helped to improve the quality of the manuscript.

Open Access This article is distributed under the terms of the Creative Commons Attribution License which permits any use, distribution, and reproduction in any medium, provided the original author(s) and the source are credited.

\section{References}

Biasutti M, Yuter SE, Burleyson CD, Sobel AH (2012) Very high resolution rainfall patterns measured by TRMM precipitation radar: seasonal and diurnal cycles. Clim Dyn 39(1-2):239-258

Chao WC (1987) On the origin of the tropical intraseasonal oscillation. J Atmos Sci 44(15):1940-1949

Collier JC, Bowman KP (2004) Diurnal cycle of tropical precipitation in a general circulation model. J Geophys Res 109:D17105

Crueger T, Stevens B, Brokopf R (2013) The Madden-Julian Oscillation in ECHAM6 and the introduction of an objective MJO metric. J Clim 26(10):3241-3257

Gill AE (1980) Some simple solutions for heat-induced tropical circulation. Q J R Meteorol Soc 106:447-462

Gregory D, Rowntree PR (1990) A mass flux convection scheme with representation of cloud ensemble characteristics and stabilitydependent closure. Mon Wea Rev 118:1483-1506

Hara M, Yoshikane T, Takahashi HG, Kimura F, Noda A, Tokioka T (2009) Assessment of the diurnal cycle of precipitation over the 
Maritime Continent simulated by a $20 \mathrm{~km}$ mesh GCM using TRMM PR data. J Meteor Soc Jpn 87A:413-424

Hendon HH, Glick J (1997) Intraseasonal air-sea interaction in the tropical Indian and Pacific Oceans. J Clim 10:647-661

Hsu HH, Lee MY (2005) Topographic effects on the eastward propagation and initiation of the Madden-Julian Oscillation. J Clim 18:795-809

Huffman GJ, Bolvin DT, Nelkin EJ, Wolff DB, Adler RF, Gu G, Hong Y, Bowman KP, Stocker EF (2007) The TRMM multisatellite precipitation analysis (TMPA): Quasi-global, multiyear, combined-sensor precipitation estimates at fine scales. J Hydrometeor $8(1): 38-55$

Hung MP, Lin JL, Wang W, Kim D, Shinoda T, Weaver SJ (2013) MJO and convectively coupled equatorial waves simulated by CMIP5 climate models. J Clim 26(17):6185-6214

Kanamitsu M, Ebisuzaki W, Woollen J, Yang SK, Hnilo JJ, Fiorino M, Potter GL (2002) NCEP-DOE AMIP-II reanalysis (R-2). Bull Am Meteor Soc 83:1631-1643

Kikuchi K, Wang B (2008) Diurnal precipitation regimes in the global tropics. J Clim 21(11):2680-2696

Kiladis GN, Wheeler MC, Haertel PT, Straub KH, Roundy PE (2009) Convectively coupled equatorial waves. Rev Geophys 47(2):RG2003

Klingaman NP, Woolnough SJ (2014a) The role of air-sea coupling in the simulation of the Madden-Julian Oscillation in the Hadley Centre model. Q J R Meteorol Soc 140(684):2272-2286

Klingaman NP, Woolnough SJ (2014b) Using a case-study approach to improve the Madden-Julian Oscillation in the Hadley Centre model. Q J R Meteorol Soc 140(685):2491-2505

Li Y, Han W, Shinoda T, Wang C, Lien RC, Moum JN, Wang JW (2013) Effects of the diurnal cycle in solar radiation on the tropical Indian Ocean mixed layer variability during wintertime MaddenJulian Oscillations. J Geophys Res Oceans 118(10):4945-4964

Lin JL, Kiladis GN, Mapes BE, Weickmann KM, Sperber KR, Lin W, Wheeler MC, Schubert SD, Del Genio A, Donner LJ, Emori S, Gueremy JF, Hourdin F, Rasch PJ, Roeckner E, Scinocca JF (2006) Tropical intraseasonal variability in 14 IPCC AR4 climate models. Part I: convective signals. J Clim 19(12):2665-2690

Love BS, Matthews AJ, Lister GMS (2011) The diurnal cycle of precipitation over the Maritime Continent in a high-resolution atmospheric model. Q J R Meteorol Soc 137:934-947

Madden RA, Julian PR (1971) Detection of a 40-50 day oscillation in the zonal wind in the tropical Pacific. J Atmos Sci 28(5):702-708

Madden RA, Julian PR (1972) Description of global-scale circulation cells in the tropics with a $40-50$ day period. J Atmos Sci 29(6):1109-1123

Madden RA, Julian PR (1994) Observations of the 40-50 day tropical oscillation-a review. Mon Wea Rev 122(5):814-837

Martin GM, Ringer MA, Pope VD, Jones A, Dearden C, Hinton TJ (2006) The physical properties of the atmosphere in the new Hadley Centre Global Environmental Model (HadGEM1). Part I: Model description and global climatology. J Clim 19(7):1274-1301

Matsuno T (1966) Quasi-geostrophic motions in the equatorial area. J Meteor Soc Jpn 44(1):25-43

Matthews AJ (2000) Propagation mechanisms for the Madden-Julian Oscillation. Q J R Meteorol Soc 126(569):2637-2651

Matthews AJ (2008) Primary and successive events in the MaddenJulian Oscillation. Q J R Meteorol Soc 134(631):439-453

Matthews AJ, Baranowski DB, Heywood KJ, Flatau PJ, Schmidtko S (2014) The surface diurnal warm layer in the Indian Ocean during CINDY/DYNAMO. J Clim 27(24):9101-9122
Moss RH, Edmonds JA, Hibbard KA, Manning MR, Rose SK, van Vuuren DP, Carter TR, Emori S, Kainuma M, Kram T, Meehl GA, Mitchell JFB, Nakicenovic N, Riahi K, Smith SJ, Stouffer RJ, Thomson AM, Weyant JP, Wilbanks TJ (2010) The next generation of scenarios for climate change research and assessment. Nature 463(7282):747-756

Neale R, Slingo J (2003) The Maritime Continent and its role in the global climate: a GCM study. J Clim 16(5):834-848

North GR, Bell TL, Cahalan RF, Moeng FJ (1982) Sampling errors in the estimation of empirical orthogonal functions. Mon Wea Rev 110(7):699-706

Peatman SC, Matthews AJ, Stevens DP (2014) Propagation of the Madden-Julian Oscillation through the Maritime Continent and scale interaction with the diurnal cycle of precipitation. Q J R Meteorol Soc 140(680):814-825

Qian JH (2008) Why precipitation is mostly concentrated over islands in the Maritime Continent. J Atmos Sci 65(4):1428-1441

Ringer MA, Martin GM, Greeves CZ, Hinton TJ, James PM, Pope VD, Scaife AA, Stratton RA, Inness PM, Slingo JM, Yang GY (2006) The physical properties of the atmosphere in the new Hadley Centre Global Environmental Model (HadGEM1). Part II: aspects of variability and regional climate. J Clim 19(7):1302-1326

Seo H, Subramanian AC, Miller AJ, Cavanaugh NR (2014) Coupled impacts of the diurnal cycle of sea surface temperature on the Madden-Julian Oscillation. J Clim 27:8422-8443

Seo KH, Kim KY (2003) Propagation and initiation mechanism of the Madden-Julian Oscillation. J Geophys Res 108(D13):4384-4405

Shaffrey LC, Stevens I, Norton WA, Roberts MJ, Vidale PL, Harle JD, Jrrar A, Stevens DP, Woodage MJ, Demory ME, Donners J, Clark DB, Clayton A, Cole JW, Wilson SS, Connolley WM, Davies TM, Iwi AM, Johns TC, King JC, New AL, Slingo JM, Slingo A, Steenman-Clark L, Martin GM (2009) U.K. HiGEM: The new U.K. high-resolution global environment model-model description and basic evaluation. J Clim 22(8):1861-1896

Simpson J, Kummerow C, Tao WK, Adler RF (1996) On the tropical rainfall measuring mission (TRMM). Meteorol Atmos Phys 60(1):19-36

Slingo A, Hodges KI, Robinson GJ (2004) Simulation of the diurnal cycle in a climate model and its evaluation using data from Meteosat 7. Q J R Meteorol Soc 130(599):1449-1467

Taylor KE, Stouffer RJ, Meehl GA (2012) An overview of CMIP5 and the experiment design. Bull Am Meteor Soc 93(4):485-498

Teo CK, Koh TY, Lo JCF, Bhatt BC (2011) Principal component analysis of observed and modelled diurnal rainfall in the Maritime Continent. J Clim 24(17):4662-4675

Wang B, Zhou L, Hamilton K (2007) Effect of convective entrainment/detrainment on the simulation of the tropical precipitation diurnal cycle. Mon Wea Rev 135(2):567-585

Wheeler MC, Hendon HH (2004) An all-season real-time multivariate MJO index: development of an index for monitoring and prediction. Mon Wea Rev 132(8):1917-1932

Wheeler MC, Kiladis GN (1999) Convectively coupled equatorial waves: analysis of clouds and temperature in the wavenumberfrequency domain. J Atmos Sci 56:374-399

Woolnough SJ, Vitart F, Balmaseda MA (2007) The role of the ocean in the Madden-Julian Oscillation: implications for MJO prediction. Q J R Meteorol Soc 133:117-128

Zhang C (2005) Madden-Julian Oscillation. Rev Geophys 43:RG2003 